\title{
Researchers' achievement goals: Prevalence, structure, and associations with job burnout/engagement and professional learning
}

\author{
Martin Daumiller \\ University of Augsburg
}

\author{
Markus Dresel \\ University of Augsburg
}

\begin{abstract}
Researchers' motivations are important for high-quality research and the productivity of the scientific system, but remain largely uninvestigated. Using three studies, we tested the usefulness of Achievement Goal Theory (AGT) for describing research motivations, investigated which goals researchers pursue, and examined their associations with job burnout/engagement and professional learning. Interviewing 20 researchers (Study 1), we found that most of their goals in the research context were classifiable as achievement goals. Apart from mastery and performance goals that are well-established in the AGT literature, they also mentioned relational and work-avoidance goals. Mastery goals comprised task and learning standards, performance goals comprised appearance and normative strivings. In Study 2, we used a standardized questionnaire to assess these goals in 824 researchers, along with burnout/engagement, professional learning time, and professional learning gains. Results confirmed the separability of all conceptualized goals, measurement invariance across academic status, and differential patterns of associations with burnout/engagement and professional learning. In Study 3, we analyzed these constructs in 471 researchers at two time points, six months apart. Results attested measurement invariance over time. Cross-lagged analyses documented similar associations as in Study 2. Learning approach and relational goals had positive effects on professional learning; appearance avoidance and workavoidance goals were negative predictors. In contrast, burnout was negatively predicted by normative avoidance goals. However, high initial burnout levels were associated with reduced task approach and learning approach, and stronger work-avoidance goals six months later. Taken together, the results highlight the usefulness of AGT for understanding researchers' motivations, and their relatedness with professional learning and well-being at work.
\end{abstract}

Keywords: Achievement goals, Research, Motivation, Burnout, Engagement, Professional learning

() 2020, Elsevier Inc. The official citation for this manuscript is: Daumiller, M., \& Dresel, M. (2020). Researchers' achievement goals: Prevalence, structure, and associations with job burnout/engagement and professional learning. Contemporary Educational Psychology, 61, 101843. https://doi.org/10.1016/j.cedpsych.2020.101843. This paper is not the copy of record and may not exactly replicate the final, authoritative version of the article. The final article will be available, upon publication, via its DOI.

\section{Introduction}

Conducting research is a primary task of academic staff at universities (Hattie \& Marsh, 1996) and is crucial for the development of society. University researchers generate most publications and "much of the most important and innovative research" (Javitz et al., 2010 , p. 4). Consequently, their research plays a decisive role in scientific and economic advancement

Correspondence concerning this article should be addressed to Martin Daumiller, Department of Psychology, University of Augsburg, Universitätsstr. 10, 86135 Augsburg, Germany; Martin.Daumiller@phil.uni-augsburg.de.

We have no known conflicts of interest to disclose.

The study presented in this paper was funded by a grant from the German Federal Ministry of Education and Research to Markus Dresel (01 HJ 0902).
(Weinberg et al., 2014), knowledge dissemination to the industry (Perkmann et al., 2013), and government decision-making (Landry, Lamari, \& Amara, 2003). Research itself is a complex, divergent, and weakly defined activity which is scarcely externally regulated. In such constellations, internal factors, such as the motivations of those conducting research, are of critical importance (see Minnaert, 2013).

The little research that has been conducted on university scholars indicates that demographic, institutional, and social-environmental factors (such as work/life balance or collegiality) explain only limited variability in experiences and behavior of faculty (Daumiller et al., 2020; Harrison \& Kelly, 1996; Ponjuan, et al., 2011; Stupnisky, Weaver-Hightower, \& Kartoshinka, 2015). Although the relevance of motivational 
characteristics has been documented for many populations and contexts, few studies have explicitly examined researchers' motivations. Initial investigations have been conducted addressing self-efficacy beliefs (e.g., Bailey, 1999; Hemmings \& Kay, 2010; Pasupathy $\&$ Siwatu, 2014), perceived personal control (Perry, Clifton, Menec, Struthers, \& Menges, 2000), self-determination (Stupnisky, Hall, Daniels, \& Mensah, 2017; Stupnisky, BrckaLorenz, Yuhas, \& Guay, 2018), and personal values (Bentley, \& Kyvik, 2013; Bland, Center, Finstad, Risbey, \& Staples, 2005; Walker \& Fenton, 2013). Investigating motivational factors of this population not only helps to better understand the differences in their experiences and behaviors at work, but also helps to provide practical indications to improve research at universities. Specifically, knowledge on researchers' motivations has the potential to contribute to the arrangement of contextual features (e.g., incentive structures), provide better support for researchers (e.g., by identifying unfavorable motivations and using scaffolds to overcome them), and align university politics (e.g., to match the personal strivings of researchers). One potential reason for the scarcity of research on the motivations of researchers is that, with the exception of self-efficacy beliefs, no motivational theory or framework has yet been successfully applied and confirmed in its adequacy and usefulness for this novel and under-investigated population - a limitation we seek to address with the present work.

As both teaching and research constitute explicit achievement contexts, and achievement goals have been successfully used to describe the motivations for teaching at schools and universities (Butler, 2007; Daumiller, Dickhäuser, \& Dresel, 2019; Daumiller, Dickhäuser, Grassinger, \& Dresel, 2016; Retelsdorf, Butler, Streblow, \& Schiefele, 2010) as well as for university scholars' vocational goal striving on a general level (without distinguishing between teaching, research, and other activities; Janke \& Dickhäuser, 2018), we applied Achievement Goal Theory (AGT) as a framework to describe motivations for research. As AGT has not yet been investigated in university researchers with respect to their research activities, an important prerequisite is to confirm the suitability of this approach. We empirically tested this by exploring the existence of achievement goals in researchers. Furthermore, as AGT specifies different goal classes, a central question is which of the goals that researchers pursue constitute distinguishable and relevant goal classes. These research questions have far-reaching consequences: The systemic differences between researchers and students/teachers can matter significantly for their goal striving and for the required theoretical framework in that different goal classes might be conflated or not even relevant. For example, researchers, in contrast to teachers, may not differentiate between task goals and learning goals, as they may consider the task of conducting research itself to already constitute learning something new. Moreover, opposed to school teachers (Butler, 2012; Butler \& Shibaz, 2014), relational goals might not be as important for researchers as these goals are directed at subjects (colleagues instead of students) that do not lie at the heart of their professional duties (but may also be relevant, as related concepts such as collegiality and the satisfaction of the psychological need for relatedness have been found to matter for university researchers; e.g., Lechuga \& Lechuga, 2012; Terosky \& Gonzales, 2016; Stupnisky et al., 2018; Stupnisky et al., 2017; Stupnisky et al., 2015). As such, knowledge about the suitability of this theoretical framework and the distinguishability and relevance of the different goal classes can be considered highly relevant and necessary for our theoretical understanding. Most importantly, this is an essential prerequisite for using this theoretical concept to describe and understand the motivations of researchers, and to examine their relations with aspects of researchers' experiences and behaviors - the second main contribution of the present work.

Regarding these relations, researchers' achievement goals can be expected to be related to burnout/engagement and professional learning - which are important factors in maintaining high quality research (see Hodgson, 2016). Specifically, in a given situation, increased burnout is often responsible when competencies do not lead to effective behaviors (Padilla \& Thompson, 2016). Conversely, professional learning is directed at the future and is responsible for the necessary continued development of competencies that is required in a fast developing research system to maintain high quality research and ensure personal sustainability (Hodgson, 2016). High levels of burnout likely also inhibit professional learning; however, researchers who are not under significant work stress also vary in the extent to which they pursue professional learning. This illustrates that, although representing different aspects of researchers' affect and behavior, it can be regarded as sensible to consider job burnout/engagement and professional learning jointly.

Based on these considerations, we conducted three studies to test the suitability of the achievement goal approach for describing the motivations of researchers, 
investigated which goals researchers pursue, and examined their associations with burnout/engagement and professional learning.

\section{Theoretical background}

\subsection{Researchers' Motivations for Research and Achievement Goal Theory}

In essence, research is systematic, creative, and often involves interpersonal work to increase knowledge (OECD, 2015). While it entails multiple different and time intensive tasks - such as literature reviews, posing research questions, data collection and analysis, discussing and interpreting findings with colleagues - an integral part is to make new knowledge public. Therefore, multiple standards are relevant that define research success, such as being innovative, managing to answer the research questions or not, achieving publications in high ranking journals, or approval of colleagues. Research is also influenced by a contest of ideas, and as such also coined by performance, particularly regarding funding, positions, and research opportunities. Finally, as research focuses on an increase in knowledge, it follows directly that learning (in terms of a longer lasting change of knowledge structures) is a central part of research, including the personal learning of individual researchers (Gordon, 2005). As such, research constitutes an explicit achievement context, in which educated, high-achieving adults are required to deliver high-quality research outcomes, successfully perform under observation, act in a social context, and constantly learn and improve. Consequently, AGT (Elliot, 2005; Maehr \& Zusho, 2009) should theoretically be suitable to describe their experiences and behaviors - such as burnout/engagement and professional learning. Being located at an intermediate level between specific target goals (focused on a specific task; see Harackiewicz \& Sansone, 1991) and the general goal contents that can subserve motivated behavior in all areas of life (see Ford, 1992), AGT refers to the goals an individual pursues in a specific achievement context — such as research (Pintrich, 2000).

Achievement goals are cognitive representations of end states in achievement-related situations that an individual is committed to either approach or avoid, with own competences often lying at the heart of these desirable or undesirable states (Hulleman, Schrager, Bodmann, \& Harackiewicz, 2010). Different affective, cognitive, and behavioral consequences have been found for the pursuit of different goal classes (Hulleman et al., 2010; Payne, Youngcourt, \& Beaubien, 2007). Original definitions (Dweck, 1986; Nicholls, 1984) distinguished between mastery goals (focused on developing competence and acquiring task mastery) and performance goals (focused on demonstrating competence and outperforming others). In the 1990s, achievement goal theorists began to additionally include the valence dimension in order to distinguish between goals focused on approaching success and goals focused on avoiding failure (Elliot \& Harackiewicz, 1996), leading to mastery approach, mastery avoidance, performance approach, and performance avoidance goals (Elliot \& McGregor, 2001). Conceptually, AGT predicts that mastery approach goals should be most favorable; empirically, the pursuit of such goals has also been found to be associated with sustained commitment, cognitive engagement, and positive immersion, however, only weak relations have frequently been reported regarding academic performance for different populations. In contrast, performance avoidance goals are typically associated with a host of unfavorable processes and outcomes (such as reduced commitment or anxiety), the effects of performance approach goals are conceptually and empirically often mixed, and mastery avoidance goals are rarely investigated (Murayama, Elliot, \& Friedman, 2012).

In the achievement goal literature, there is still disagreement about the nature of these four goals and the necessity of more finely differentiating them (Brophy, 2005; Elliot, 2005; Grant \& Dweck, 2003; Hulleman et al., 2010). In any case, contradicting results have been reported for mastery and performance based goals, leading to a lack of clarity. Therefore, a finer differentiation of these goals may be warrented to clarify their various effects for experiences and behaviors - in particular, as the need for these further differentiations might depend on the population at hand. Regarding performance goals, two components have been identified that can be considered empirically distinct and differently related to educational outcomes (Elliot, 1999, 2005; Hulleman et al., 2010; Lee \& Bong, 2016; Senko \& Dawson, 2017; Urdan \& Mestas, 2006): an appearance component (wanting to be perceived as competent, or not wanting to be perceived as incompetent, irrespective of personal performance) and a normative component (wanting to be more competent than others, or not wanting to be worse than others, concerning actual performance). Similarly, two aspects have also been distinguished for mastery goals (e.g., Elliot, Murayama, \& Pekrun, 2011) according to whether the standard for evaluating one's own competence lies in the task (termed as task goals throughout this manuscript) or in intrapersonal development (termed as 
learning goals throughout this manuscript). Lastly, in the literature on achievement goals, two further goal classes have been proposed (see Butler, 2014): work avoidance goals (striving to get through the day with little effort) and relational goals (striving to create close and caring relationships). The question of whether or not to classify these two further goals as achievement goals has been a topic of controversial discussion within the literature, as they are typically unrelated to individual definitions of competence (Elliot \& Hulleman, 2017; Murayama et al., 2012). Nevertheless, they are seen as helpful in describing the beliefs and aims of achievement behavior and the evaluation criteria that are used to describe whether an action was successful or not (Urdan, 1997). This is particularly the case for achievement contexts such as research that is also frequently an interpersonal endeavor containing multiple time-intensive tasks as described above. We therefore use a definition of achievement goals that is based on the definition and valence of competence and also includes work avoidance and relational goals as additional, complementing goals that matter in achievement situations.

Daumiller et al. (2019) focused these finer differentiations of achievement goals while analyzing the goals of university faculty for teaching. The authors distinguished six different types of goal content (learning, task, normative, and appearance, as well as the two additional work avoidance and relational aspects; see Table 1). For each of the two facets of mastery goals and performance goals, an approach and an avoidance component is postulated in this conceptualization, while work avoidance goals are avoidance-based by definition, and relational goals are conceptualized as approach-based goals. These assumptions result in a framework with ten theoretically distinguishable goal classes. The authors empirically tested this framework with a sample of 1,066 university instructors. It was found that full professors, postdoc staff members, and staff members without a $\mathrm{PhD}$, equally and clearly distinguished between these different goal classes. Theoretically sensible relationships with positive affect, attitudes towards help-seeking, and teaching quality affirmed their convergent validity (e.g., normative approach/avoidance goals were positively/negatively related with positive affect while appearance approach/avoidance goals were not, but were instead positively/negatively related to teaching quality).

While achievement goals have already been investigated in the teaching domain, the question of which goals are pursued in the research domain and whether they matter remains unanswered. In the present work we investigate this issue. To allow for specific conclusions, we use the finer differentiation of achievement goals proposed by Daumiller et al. (2019). Based on the

Table 1

Overview of Proposed Goal Classes and their Definitions (Based on Butler, 2012; Daumiller et al., 2019; Elliot, 2005; Elliot et al., 2011; Grant \& Dweck, 2003; Hulleman et al., 2010), and Sample Items (Studies 2 and 3)

\begin{tabular}{|c|c|c|c|c|}
\hline $\begin{array}{l}\text { Superordinate } \\
\text { goal class }\end{array}$ & Goal content & Valence & Definition (striving toward) & $\begin{array}{l}\text { Sample items (item stem: In my current } \\
\text { research activities, ...) }\end{array}$ \\
\hline \multirow[t]{4}{*}{ Mastery } & \multirow[t]{2}{*}{ Task } & Approach & $\begin{array}{l}\text { Doing well on a task, based on its own } \\
\text { standard }\end{array}$ & $\begin{array}{l}\text {... I want to fulfill the different requirements } \\
\text { very well. }\end{array}$ \\
\hline & & Avoidance & $\begin{array}{l}\text { Avoiding doing poorly on a task, based on its } \\
\text { own standard }\end{array}$ & $\begin{array}{l}\text {.. I want to avoid fulfilling the different } \\
\text { requirements poorly. }\end{array}$ \\
\hline & \multirow[t]{2}{*}{ Learning } & Approach & Developing and growing own competencies & $\begin{array}{l}\text {... my goal is to expand my professional and } \\
\text { methodological knowledge as much as } \\
\text { possible. }\end{array}$ \\
\hline & & Avoidance & $\begin{array}{l}\text { Avoiding losing own competencies or not } \\
\text { developing them }\end{array}$ & $\begin{array}{l}\text {... my goal is not to leave the opportunities } \\
\text { to expand my professional and } \\
\text { methodological knowledge untapped. }\end{array}$ \\
\hline \multirow[t]{4}{*}{ Performance } & \multirow[t]{2}{*}{ Appearance } & Approach & Appearing competent to others & ... I want to be perceived as competent. \\
\hline & & Avoidance & Avoiding appearing incompetent to others & $\begin{array}{l}\text {... I want to avoid being perceived as } \\
\text { incompetent. }\end{array}$ \\
\hline & \multirow[t]{2}{*}{ Normative } & Approach & Being more competent than others & $\begin{array}{l}\text {... my goal is to do better research than my } \\
\text { colleagues. }\end{array}$ \\
\hline & & Avoidance & Avoiding being less competent than others & $\begin{array}{l}\text {... my goal is not to do worse research than } \\
\text { my colleagues. }\end{array}$ \\
\hline \multirow[t]{2}{*}{ Further goals } & Work avoidance & & Getting through the day with little effort & $\ldots$ it is important to me to have little to do. \\
\hline & Relational & & $\begin{array}{l}\text { Creating close and caring relationships with } \\
\text { other researchers }\end{array}$ & $\begin{array}{l}\ldots \text { it is important to me to achieve a personal } \\
\text { connection with my colleagues. }\end{array}$ \\
\hline
\end{tabular}


findings in the teaching domain, it seems plausible that all of these goals may also be pursued in the research domain, irrespective of researchers' academic status (i.e., the structure should equally hold true for full professors, postdoc staff members, and staff members without a $\mathrm{PhD}$ ). This assumption needs to be specifically confirmed, as even within the same job and culture, groups of individuals might understand or value items differently based on their academic and professional socialization (see Schmitt \& Kuljanin, 2008).

Taken together, we cannot simply assume that researchers do indeed pursue the achievement goals mentioned above and transfer existing scales to the research domain without risking assessing artifacts or limiting the range or content of the goals in question (Dowson \& McInerney, 2001). Instead, it first needs to be confirmed that researchers do indeed pursue such goals. Only then can their separability, invariance for different subgroups, and important relations with experiences and behaviors be adequately tested.

Based on theoretical assumptions of the nature of goal striving and the established empirical importance of achievement goals for burnout/engagement and using learning opportunities (Nitsche, Dickhäuser, Dresel, \& Fasching, 2013; Nitsche, Dickhäuser, Fasching, \& Dresel, 2013; Payne et al., 2007; Tönjes \& Dickhäuser, 2009), it seems plausible that achievement goals are systematically related with researchers' burnout/engagement and professional learning, as we will describe in the following sections.

2.2 Researchers' Job Burnout/Engagement and its Association with Achievement Goals

Experiences of stress and strain in the professional arena are commonly associated with the term "burnout", first used in the 1970s to describe a pathological state of prolonged stress response (Freudenberger, 1974). Maslach and Leiter (2008) elaborated on this concept by describing burnout as an erosion of engagement within the job. As such, this concept constitutes a continuum running from a positive pole (engagement) to a negative pole (burnout) of handling work situations. It is constituted by subjective perceptions of reactions to stress factors, which, according to Maslach, Jackson, and Leiter (1996), can be described as emotional exhaustion (feeling depleted and no longer interested in one's occupation), cynicism (a distanced attitude to work in general), and reduced personal accomplishment (experiencing limited performance and a reduced meaningfulness of one's work).
For university researchers, the experience of burnout appears also to be significant. According to Lackritz (2004), approximately $20 \%$ of university faculty members experience high burnout levels. Similarly, Blix, Cruise, Mitchell, and Blix (1994) found high burnout levels in 158 surveyed university scholars, two thirds of which reported perceiving work stress at least half of the scheduled time. Moreover, Singh, Mishra, and Kim (1998) surveyed 328 researchers working at a mid-sized US university and found them to have high burnout levels, which were negatively related to intrinsic motivation to do research. Beyond impaired well-being, the experience of burnout/engagement is also important as it makes a substantial contribution to the decision of whether or not to remain in the university system (Jaksztat, Preßler \& Briedis, 2012). In explaining these strong experiences of job burnout in academia, the investigation of personal (especially motivational) factors is often neglected (Barkhuizen, Rothmann, \& Van De Vijver, 2013). However, as illustrated in a recent review by Sabagh, Hall, and Saroyan (2018), personal aspects such as motivations are significantly related to faculty burnout beyond background factors, task demands, and stressors. As achievement goals are responsible for the interpretation of achievement situations and the focus of thoughts and behaviors, it should follow that they matter for the experience of burnout. Specifically, the relevance of achievement goals for coping with stressors, and as such individuals' burnout/engagement, can be explained as the motivational systems spanned up by focusing on different achievement goals can be regarded as resources or determinents of individuals' primary and secondary appraisals of stressors (Folkman, Lazarus, Dunkel-Schetter, DeLongis, \& Gruen, 1986): For instance, a conference presentation might be interpreted as positive for individuals with strong learning goals, and as dangerous for individuals with strong appearance avoidance goals. Besides this theoretical reasoning, empirical findings on teachers also support the link between achievement goals and burnout/engagement (Tönjes \& Dickhäuser, 2009).

Specifically, as mastery approach goals are focused on the development of competencies and conducting work tasks well, they should be associated with a perception of (even stressful and exhausting) achievement situations as positive and controllable, and therefore go along with reduced burnout levels. Indeed, research on school teachers has consistently reported negative associations between such goals and burnout experiences (Retelsdorf et al., 2010; Tönjes \& Dickhäuser, 2009) and found that these goals positively predict the amount 
of coping strategies used in stressful situations (Parker, Martin, Colmar, \& Liem, 2012). Therefore, we expected negative associations between mastery approach goals and researchers' burnout levels; regarding mastery avoidance goals we had no specific assumptions due to their combination of a favorable masteryfocus with the unfavorable avoidance-component and the lack of empirical findings on this type of goal.

Similarly, performance approach goals are composed with an unfavorable focus on performance while their valence is favorable, which does not allow clear theoretical expectations. On the empirical level, no associations have been reported for these goals with burnout/engagement or related constructs such as satisfaction (Janssen \& van Yperen, 2004; Nitsche, Dickhäuser, Fasching, et al., 2013; van Yperen \& Jansssen, 2002). As such, the relevance of performance approach goals for researchers' job burnout/engagement is unclear.

Individuals strongly pursuing performance avoidance goals can be expected to perceive achievement situations as threatening and to be worried about failure. Empirically, clearly negative associations with burnout have been reported (Papaioannou \& Christodoulidis, 2007; Retelsdorf et al., 2010; Tönjes, Dickhäuser, \& Kröner, 2008). Furthermore, research on school teachers supports the notion that normative strivings for performance are specifically associated with the development of high burnout levels (Friedman, 2000). However, against the background of the adverse relation between the use of self-presentation strategies and individual well-being (Giacalone \& Promislo, 2014), it is possible that appearance aspects may also be relevant. Therefore, we expected positive associations for performance avoidance goals with burnout levels, however, we did not have specific hypotheses concerning their focus on appearance or normative standards.

We found no studies that investigated relational goals and burnout/engagement, and had no clear theoretical expectations as to how these might be related. Finally, we expected positive associations between work avoidance goals and the burnout levels of researchers, given that work avoidance likely limits the available resources for dealing with work stress and can be considered an adverse coping strategy over time (Salmela-Aro, Volvanen \& Nurmi, 2009) while empirically having been associated with the amount of sick days as well as burnout levels (Retelsdorf et al., 2010; Nitsche, Dickhäuser, Fasching, et al., 2013).
2.3 Researchers' Professional Learning and its Association with Achievement Goals

Professional learning - e.g., in terms of improving one's own cognitive representation of a research object or the methods for its analysis and application - is a key characteristic of conducting research. Being involved in professional learning is of great importance for researchers as it can lead to the advancement of research competencies (e.g., methodology, writing, presentation, and strategic skills) and ultimately enhance research productivity (Evans, 2011; Gordon, 2005). Professional learning can be divided into formal (e.g., participation in organized workshops or courses) and informal (e.g., reading reviews of submitted manuscripts, discussing specific analyses with colleagues) learning (Marsick \& Watkins, 1990) that should both be included to adequately describe professional learning (see Trautwein \& Merkt, 2013).

It is commonplace in psychology that it is important to distinguish between the learning process and learning outcomes. This can be illustrated for example by processual models of self-regulated learning (e.g., Schmitz \& Wiese, 2006; Zimmerman, 2000), which typically involve three phases: forethought/pre-actional, performance/actional, and self-reflection/postactional. Goals are considered to be important in the forethought/pre-actional phase of these models and influence, among other aspects, learning time in the performance/actional phase, which in turn impinge on quantitative and qualitative learning outcomes, emotions, and reactions. Particularly, learning time has been reported as the strongest predictor for actual learning in a recent meta-analysis (Schneider \& Preckel, 2017).

Concerning factors influencing the use of learning opportunities, the literature indicates that personal aspects are important (e.g., meta-analysis by Colquitt, LePine, \& Noe, 2000), especially those relating to motivation (Chiaburu \& Marinova, 2005; Grossman \& Salas, 2011; Volet, 2013). The important role of motivation in the success of learning activities is explicitly mentioned in theoretical models on vocational training (Baldwin \& Ford, 1988; Cannon-Bowers, Salas, Tannenbaum \& Mathieu, 1995) and the relevance of achievement goals in particular is documented in a wide array of theoretical and empirical investigations (e.g., Payne et al., 2007).

Specifically, as mastery goals focus on personal development, they can be considered highly favorable for professional learning. A comprehensive meta-analysis by Payne et al. (2007) documented positive associa- 
tions between these goals and learning gains. Additionally, studies in occupational settings have reported linkages between learning goals and participation in development activities (Hurtz \& Williams, 2009; Nitsche, Dickhäuser, Dresel, et al., 2013). As occupational settings entail a multitude of different tasks (out of which only a few are directly focused on learning, whereas tasks of students are mostly directed at learning), we assumed positive associations between learning goals and the learning process and learning outcomes; however, we had no clear expectations for task goals.

For learning avoidance goals, negative associations have been reported regarding learning gains in experimental tasks (van Yperen, Elliot, \& Anseel, 2009). As learning avoidance goals can, based on their valence, be expected to go along with a rather negatively connoted general attitude (Elliot et al., 2011), we also assumed them to be associated with impaired learning outcomes in researchers (however, we had no expectations concerning learning time).

For the relationship between performance approach goals and learning gains, both negative and positive associations have been reported as well as no associations at all (e.g., Payne et al., 2007; Nitsche, Dickhäuser, Dresel, et al., 2013; Nitsche, Dickhäuser, Fasching, et al., 2013). As also no clear theoretical expectations are evident (the positive valence might energize behavior, but the focus on performance might not lead to learning behaviors), we had no clear hypotheses on this goal class for researchers.

For performance avoidance goals and learning gains, negative results have clearly and consistently been reported in the literature in different populations (e.g., Pintrich, 2000; Payne et al., 2007; Nitsche, Dickhäuser, Dresel, et al., 2013). This is in line with theoretical reasoning about this type of goal: Individuals with strong performance avoidance goals likely actively avoid learning opportunities, as such situations often include the risk of making errors that could be easily perceived as revealing personal incompetence. Therefore, we hypothesized negative associations for researchers, but did not have clear expectations as to whether these effects might differ between the goals being focused on appearance or normative aspects.

Concerning relational goals, we expected that researchers with a strong desire to interact with colleagues might also more actively pursue situations where they can attain these goals (e.g., consulting colleagues for help, or attending workshops) and consequently also learn more (see also Terosky and Gonzales, 2016, on the relevance of colleagues for scholarly learning).
Lastly, for work avoidance goals, we expected negative associations with learning processes and outcomes, as learning activities involve using personal resources (e.g., cognitive capacity, time) which individuals with work avoidance goals strive to preserve. This is in line with findings on work avoidance goals and their associations with students' use of maladaptive learning strategies (Nolen, 1988), and school teachers' use of professional learning opportunities (Nitsche, Dickhäuser, Dresel, et al., 2013; Nitsche, Dickhäuser, Fasching, et al., 2013).

Research on the achievement goals of other populations allows for the above mentioned specific, yet preliminary, predictions on what associations to expect for researchers. However, apart from their focus on populations other than researchers, a crucial limitation of these findings is that they are predominantly cross-sectional.

2.4 Causal Ordering of Achievement Goals, Job Burnout/Engagement, and Professional Learning

AGT is rooted in the notion that achievement goals are responsible for the interpretation of achievement situations, and the experiences and behaviors therein (McGregor \& Elliot, 2002). Thus, it is reasonable to assume that achievement goals influence learning behavior as well as the formation of job burnout. However, reciprocal relationships might also exist-although they have been largely neglected, as AGT research has mostly focused on unidirectional effects of goals on outcomes (see King \& McInerney, 2016).

Following the rationale of the dynamic nature of goal pursuit (humans regarded as self-regulating systems; DeShon \& Gillespie, 2005) it is reasonable to assume that goals and outcomes such as job burnout/engagement might reciprocally influence each other over time. This was already underpinned empirically in a study by King and McInerney (2016) that indicated, in a sample of 8,773 secondary school students, that mastery goals were reciprocally associated with the use of metacognitive strategies and predicted by academic achievement.

While effects from goals on learning behaviors are theoretically sensible, it should be considered that learning behaviors may also impact subsequent goal setting processes (e.g., having learned a lot, one might develop stronger learning avoidance goals in order to avoid losing the newly developed competences, or one might want others to notice one's increased competences by pursuing stronger appearance approach goals). Especially for job burnout/engagement, causal 
effects seem plausible in both directions. On the one hand, it can be argued that achievement goals influence the development of burnout/engagement levels (e.g., being concerned about performance could render achievement situations as subjectively more stressful and exhausting). On the other hand, the reverse direction also seems plausible (e.g., if individuals are confronted with a lot of stress at work, they might begin to pursue strong work avoidance goals as a coping mechanism). Furthermore, it should be acknowledged that there may be no general causal ordering of these variables, but instead, the directions might depend on the individual goal classes.

\subsection{The Present Research}

In the present research, we aimed to expand the sparse research on the motivations of researchers and investigate their connection with burnout/engagement and learning at work. Specifically, we aimed to confirm that AGT is well suited for describing researchers' motivations (i.e., that most of the goals they pursue can be classified as achievement goals), to investigate the prevalence and structure of these goals, and to analyze how they are related to job burnout/engagement and professional learning as important factors for reaching and maintaining high quality research. Regarding the effects of goals on professional learning processes and outcomes, we distinguish between the more proximal learning time as well as learning gains that constitute a more distal variable.

In the first instance, we wanted to investigate the prevalence of achievement goals, specifically regarding the whole range of achievement goal classes that we theoretically distinguished (see Table 1). To this end, we had the fundamental assumption that all of the proposed goal classes are pursued by researchers (as indicated by respective responses to open-ended questions on their goals).

Building on this, and considering the finer differentiations of achievement goals based on theoretical reasoning and the first empirical findings in this regard (Daumiller et al., 2019; Elliot, 2005; Hulleman et al., 2010; Lee \& Bong, 2016; Senko \& Dawson, 2017), we aimed to investigate the structure of these goals. To this end, we formulated the following hypothesis:

H1: The proposed goal distinction describes researchers' achievement goal pursuit well (i.e., shows a good fit to the data) and better than alternative models (conflating different facets).
As this structure and the understanding and valuation of items assessing different goals might vary between researchers based on their status (see also Schmitt \& Kuljanin, 2008), we subsequently also sought to confirm its invariance across different academic status groups (full professors, postdoc staff members, and staff members without a $\mathrm{PhD}$ ) in a set of additional analyses.

Finally, we wanted to analyze how researchers' achievement goals relate to their job burnout/engagement and professional learning:

H2: Researchers' achievement goals are differentially associated with their job burnout/engagement, professional learning time, and professional learning gains.

For this hypothesis, we had specific expectations for each type of goal (see the previous sections for these expectations). Additionally, based on the dynamic nature of goal pursuit, we acknowledged possible reciprocal effects. Regarding professional learning, we expected that the predominant causal direction includes goals influencing professional learning. With regard to job burnout/engagement, we expected that both causal effects from goals on burnout/engagement and, vice versa, causal effects from burnout/engagement on goals are evident.

To test our assumptions and hypotheses, we conducted three studies: an interview study that primarily served to investigate the actual (i.e., non-reactive) occurrences of achievement goals in researchers, a crosssectional study to analyze the structure of these goals and to gain a first insight into their associations with job burnout/engagement and professional learning $(\mathrm{H} 1$, $\mathrm{H} 2$ ), and a study with two measurement points to investigate the temporal ordering of these effects $(\mathrm{H} 2)$. All studies were conducted with researchers from German universities and were in full accordance with the Ethical Guidelines of the German Association of Psychologists and the American Psychological Association. Full anonymity was assured and we had no reason to assume that participation in our studies would have any negative effects on the researchers.

To understand the investigated samples of scholars from German universities, it is helpful to point to a key difference between the German higher education system and countries such as the US. In the German higher education system, graduate students pursuing a $\mathrm{PhD}$ are typically part of the academic staff. They are often hired with at least a half-time contract as a faculty member, entailing both teaching and research responsibilities, and are also provided with an office space (see 
Wosnitza, Helker, \& Lohbeck, 2013, for a more detailed description). Given this background, the investigated samples include also academic staff members without a PhD. ${ }^{1}$

\section{Study 1}

\subsection{Method}

The aim of Study 1 was to investigate the actual occurrences of achievement goals in researchers. Using guided, half-standardized interviews with open-ended questions, we interviewed researchers about their goals in research. Such an open approach is generally rare in research on achievement goals but required to investigate and confirm important theoretical assumptions, particularly regarding the existence and content of the different goal classes (Brophy, 2005; Lee \& Bong, 2016). We took great care to represent a broad spectrum of participants. Each interview lasted for an average of 30 minutes.

Participants. We sampled 20 researchers, $40 \%$ of which were female, $80 \%$ younger than 40 years, and $10 \%$ older than 50 years. Altogether $40 \%$ had a $\mathrm{PhD}$ and four were full professors. They were from the mathematical and natural sciences (4), educational sciences (6), historical sciences (4), political sciences (3), and media and communication sciences (3). We ex ante set the sample size to 20 and used the principles of theoretical sampling to adequately represent combinations of academic status, gender, age, and field of the researchers. To recruit the final sample, we reached out to a total of 24 researchers ( 2 of which stated that they would not find time for the interview and 2 of them did not respond).

Procedure. We asked the interviewees about a date, time, and location that was convenient for them to conduct the interview. All interviews were held during the regular work day of the researchers in their offices. To reduce distortions due to interviewer effects, all interviews were conducted by one, trained, external research assistant. First, participants were asked to narrow their answers down regarding their main research area. As goals need not always be explicitly consciously prevalent (Austin \& Vancouver, 1996), we split the interview into two parts. In the first part, we asked the open question of "What personal strivings do you have in your current research? What personal aims do you pursue there?" Goals that were mentioned in response to these questions were classified as spontaneously articulated in the analysis. In the second part, we carefully asked questions in the direction of the proposed content goal classes (e.g., for learning approach and learning avoidance goals: "Doing research, a main concern is to expand the scientific knowledge. However, apart from investigating the research topic at hand, you as a researcher of course also have the possibility to expand your own personal knowledge and your skills. [...] To what extent are you concerned, in doing research, to also expand your own skills or knowledge, or not to forget things you already know or can do?"). We classified the subsequently mentioned goals as reactively articulated. Together with the participants, the interviewer segmented their answers into individual goals, by writing each goal down on a separate paper (and asking the interviewee if this was correct). By doing so, it was ensured that the amount and distinctness of the individual goals was adequately assessed. Afterwards, we asked the interviewees to rate the perceived importance of each goal on a Likert-type scale ranging from 1 (not important at all) to 10 (very important).

Analyses. All interviews were transcribed and coded by two raters through a category system that was based on the proposed goal structure (we provide the category system and its category tree in Table S1 and Figure S1 in the electronic supplement). Here, we checked in a first step if the mentioned answers were indeed goals in the sense of representations of end states that the individual is committed to either approach or avoid (Hulleman et al, 2010). All responses that could not be identified as goals were classified in a no-goal category and not included in the subsequent analyses $(<5 \%)$. Further, we expected that researchers would, although they were asked about their personal goals, mention goals directed at the output of their research activities. As these goals are not directed at the own person in marked-off achievement situations, we classified them in a separate category, titled output goals. For the remaining (personal) goals of the researchers, our category system distinguished the ten goals described in Table 1. All remaining goals that could not be classified as one of these goals were coded as other goals. The inter-rater reliability (between two trained raters) across the whole category system was $\kappa=.86$.

\subsection{Results and Discussion}

The interviewed researchers mentioned on average 14 goals $(S D=3$, altogether 262), of which $52.3 \%$ were spontaneously articulated (see Table 2 ). Only very few 
Table 2

Type, Amount, and Importance of Goals Articulated in Study 1

\begin{tabular}{|c|c|c|c|c|c|c|}
\hline \multirow[t]{2}{*}{ Goal class } & \multirow[t]{2}{*}{ Example excerpts } & \multicolumn{2}{|c|}{ Overall } & \multicolumn{2}{|c|}{ Spontaneous } & \multirow{2}{*}{$\frac{\text { Importance }}{M(S D)}$} \\
\hline & & $f$ & $\%$ & $f$ & $\%$ & \\
\hline Achievement goals & & 223 & 100 & 101 & 100 & $8.5(1.7)$ \\
\hline Task approach & $\begin{array}{l}\text { "It's my goal to diligently review the literature"; "I strive after good } \\
\text { quality, not quantity" }\end{array}$ & 51 & 100 & 22 & 65 & $9.1(1.3)$ \\
\hline Task avoidance & $\begin{array}{l}\text { "I want to avoid doing poor quality research"; "I want to avoid } \\
\text { doing my research badly" }\end{array}$ & 10 & 50 & 4 & 10 & $8.0(3.2)$ \\
\hline Learning approach & $\begin{array}{l}\text { "My main aim is to improve myself"; "expanding my skills is very } \\
\text { important to me" }\end{array}$ & 48 & 100 & 39 & 80 & $8.9(1.4)$ \\
\hline Learning avoidance & $\begin{array}{l}\text { "It's important not to leave out learning opportunities"; "I want to } \\
\text { avoid my skills to crust" }\end{array}$ & 7 & 30 & 2 & 10 & $9.1(1.5)$ \\
\hline Appearance approach & $\begin{array}{l}\text { "At a conference, it's my goal to make a really good impression"; } \\
\text { "My aim is to be perceived as very competent" }\end{array}$ & 32 & 95 & 12 & 30 & $8.5(1.2)$ \\
\hline Appearance avoidance & $\begin{array}{l}\text { "I don't want to make a fool of myself"; "One of my goals is to } \\
\text { conceal my bad spots [e.g., skills]" }\end{array}$ & 13 & 50 & 3 & 10 & $7.6(3.1)$ \\
\hline Normative approach & $\begin{array}{l}\text { "to be better, more convincing than others"; "I want to be a better } \\
\text { researcher than others" }\end{array}$ & 21 & 65 & 10 & 20 & $8.4(2.0)$ \\
\hline Normative avoidance & $\begin{array}{l}\text { "I don't want to be worse"; "I want to avoid doing worse research } \\
\text { than my colleagues" }\end{array}$ & 8 & 30 & 0 & 0 & $8.8(1.9)$ \\
\hline Work avoidance & $\begin{array}{l}\text { "building up synergies to avoid work"; "Sometimes it's an important } \\
\text { goal for me to save resources"; "get through demanding situations } \\
\text { with little effort" }\end{array}$ & 9 & 30 & 0 & 0 & $7.3(0.8)$ \\
\hline Relational & $\begin{array}{l}\text { "this social factor is an important goal for myself in research"; "I } \\
\text { strive after good relations with my fellow researchers" }\end{array}$ & 24 & 80 & 9 & 35 & $8.9(0.8)$ \\
\hline Other goals & "I want to work independently"; "I want to make good money" & 17 & 60 & 16 & 50 & $8.4(1.3)$ \\
\hline Output goals & $\begin{array}{l}\text { "I want to advance the field I am working in"; "at the end of the day } \\
\text { I want practitioners to have specific guidelines"; }\end{array}$ & 22 & 80 & 20 & 70 & $9.0(1.2)$ \\
\hline
\end{tabular}

Notes. $N=20$. Reported are the absolute frequencies of goals $(f)$, and the amount of researchers that mentioned them (\%) as well as the importance of each goal (overall mean, theoretical range: 1-10). For each goal class, interview excerpts are given as examples.

goals $(<7 \%)$ were classified as other goals (which were primarily directed at the balance between research and other duties, and the security of one's job), meaning that the vast majority of all personal goals were classified as achievement goals. Furthermore, for each goal it was clear whether an approach or an avoidance goal was mentioned (i.e., no task, learning, appearance, or normative goals, for which the approach or avoidance direction was not specified, were articulated) which indicates that the participants were capable of distinguishing between goal valences. The spontaneously and reactively articulated goals together showed that all of these goal classes, including controversially discussed goals, such as learning avoidance goals, were reported by at least one third of the participants, while different researchers pursued different goals. This indicates that all proposed goal classes exist in the research domain and that an achievement goal perspective constitutes a sensible framework for describing researchers' motivations.

The content of task approach and avoidance goals was wide-spread and primarily focused on conducting research tasks, the amount and quality of publications, as well as presentations in front of colleagues. The researchers articulated clear standards that were immanent in the tasks and that they sought after (e.g., doing research tasks such as literature reviews very diligently and thoroughly, making sure that their presentations conform to scientific standards; see Table 2 for further examples). Learning approach and learning avoidance goals were directed at intra-individual development. We observed a focus on the development of method or soft skills, or on improving one's knowledge about the research topic and the research methods used. Two of the interviewees also stated that having such goals really mattered to them because they considered these goals to drive them to use many professional learning opportunities. Appearance approach and appearance avoidance goals were primarily directed at public appearance or specific, important others (such as supervisors; see also Nitsche, Dickhäuser, Fasching, \& Dresel, 2011; Ziegler, Dresel, \& Stoeger, 2008). In regard to these groups of people, the researchers articulated that they were aiming for a good (or not a bad) impression. Similarly, normative approach and avoidance goals 
were directed at public performance or performance in comparison to colleagues. The researchers based this performance on clear, normative comparisons with other researchers (e.g., wanting to have more or better publications than other researchers). Work avoidance goals were focused on a reduction of work and encompassed a spectrum of underlying themes ranging from primarily leisure oriented work reduction to efficiency oriented work reduction (e.g., by synergistically combining teaching and research, or different research topics). Three interviewees also highlighted the importance of this type of goal as a crucial coping strategy in times of high stress and pressure. As such, work avoidance goals encompassed different reasons behind goal pursuit while being focused on the same aim. Lastly, relational goals were directed at having a good connection with colleagues as well as good relations that also provide support and a positive work climate.

Although the manifestations of the individual goals varied between and within researchers (e.g., in being mentioned in regard to different tasks), the psychological foci and orientations of the goals were consistent. In particular, they closely aligned with the theoretical definitions of the goals (see Table 1; with the only exception being work avoidance goals which were marginally broader) and had the same underlying nature and definition as the respective goals in other domains (such as achievement goals for teaching) despite being directed at different addressees (e.g., fellow researchers instead of students) and objects (e.g., research tasks instead of teaching tasks). One methodic consequence of this substantial conclusion is that using questionnaires to assess these goals is adequate (in the sense of not assessing artificial constructs that do not occur naturally) and that scales from other domains that match onto the same underlying goal definitions can be adapted to the research domain (by changing addressees and objects). Furthermore, the variations in the different manifestations of the goals within the interviewed researchers - that were based on the principles of theoretical sampling to ensure a broad selection regarding age, gender, academic status, and field-were rather small and not specific for the research context of the investigated sample (such as the German university context). We take this as an indication of the generalization of the concept of achievement goals of researchers in other research contexts (such as countries or institutions with different incentive systems).

When interpreting the findings, it should be noted that we interviewed the researchers during their regular work days. As such, their answers might have been affected by recency effects. However, as these effects are unsystematic, they likely do not impair the interpretability of the results. Furthermore, avoidance goals were mentioned less frequently, and less spontaneously, than approach goals (47 vs. 176 in total), which could indicate that they are less consciously available or might point to social desirability issues inherent in the interview situation (see for instance the low occurrence of work avoidance goals or the differences between approach and avoidance goals of the same goal content). This additionally supports the idea of assessing achievement goals with questionnaires (which are not unsusceptible, but less amendable to social desirability issues; Gnambs \& Kaspar, 2015).

\section{Study 2}

\subsection{Method}

The aim of Study 2 was to analyze the structure of researchers' goals and to gain a first insight into their associations with job burnout/engagement and professional learning $(\mathrm{H} 1, \mathrm{H} 2)$. To this end, researchers responded to an online questionnaire assessing their achievement goals, job burnout/engagement, professional learning time and professional learning gains, as well as biographic information. They received a small incentive after participating in the study ( $5 €$ voucher). We chose ten fields (biology, business studies, economics, educational science, English studies, German studies, mathematics, pharmaceutics, political sciences, and sports science) that represent a range of typical research fields in the natural sciences, social sciences, and humanities, identified all research universities in Germany where they were represented, and randomly selected researchers who were subsequently contacted by e-mail (response rate: $31 \%$ ).

Participants. Altogether, 824 German university researchers participated ( 240 full professors, 264 postdoc staff members, 320 staff members without a $\mathrm{PhD}$; 420 males, 404 females; mean age: 39.0 years, $S D=12.1$ years; $8-12 \%$ from each field). Comparing the descriptive composition regarding age, gender, and academic status of our sample with nationwide statistics (German Federal Statistical Office, 2016) shows that our sample is sufficiently representative of the investigated fields regarding these characteristics.

Measures. We asked the participants about their achievement goals, job burnout/engagement, professional learning time, and professional learning gains. ${ }^{1}$ Internal consistencies of all scales are provided in Table 3 (all $\omega \geq .78$ ). 
Descriptive Statistics and Latent Correlations in Study 2

\begin{tabular}{|c|c|c|c|c|c|c|c|c|c|c|c|c|c|c|c|c|c|c|c|c|}
\hline & $M$ & $S D$ & $\omega$ & Min & Max & Skew & 1 & 2 & 3 & 4 & 5 & 6 & 7 & 8 & 9 & 10 & 11 & 12 & 13 & 14 \\
\hline \multicolumn{21}{|l|}{ Mastery goals } \\
\hline [1] Task approach & 7.24 & 0.80 & .78 & 1.00 & 8.00 & -1.36 & & & & & & & & & & & & & & \\
\hline [2] Task avoidance & 6.43 & 1.54 & .88 & 1.00 & 8.00 & -1.03 & .59 & & & & & & & & & & & & & \\
\hline [3] Learning approach & 7.25 & 0.86 & .87 & 2.00 & 8.00 & -1.20 & .79 & .47 & & & & & & & & & & & & \\
\hline [4] Learning avoidance & 6.56 & 1.33 & .82 & 1.00 & 8.00 & -1.01 & .60 & .55 & .67 & & & & & & & & & & & \\
\hline \multicolumn{21}{|l|}{ Performance goals } \\
\hline [5] Appearance approach & 6.21 & 1.31 & .88 & 1.00 & 8.00 & -0.99 & .57 & .46 & .40 & .41 & & & & & & & & & & \\
\hline [6] Appearance avoidance & 6.24 & 1.52 & .87 & 1.00 & 8.00 & -1.09 & .35 & .60 & .23 & .37 & .70 & & & & & & & & & \\
\hline [7] Normative approach & 4.85 & 1.79 & .93 & 1.00 & 8.00 & -0.33 & .40 & .36 & .25 & .30 & .73 & .46 & & & & & & & & \\
\hline [8] Normative avoidance & 5.56 & 1.72 & .91 & 1.00 & 8.00 & -0.63 & .40 & .61 & .31 & .42 & .76 & .78 & .72 & & & & & & & \\
\hline \multicolumn{21}{|l|}{ Further goals } \\
\hline [9] Work avoidance & 2.00 & 1.23 & .91 & 1.00 & 7.50 & 1.15 & -.46 & -.16 & -.40 & -.26 & -.05 & .05 & .05 & .02 & & & & & & \\
\hline [10] Relational & 5.47 & 1.58 & .88 & 1.00 & 8.00 & -0.52 & .24 & .22 & .23 & .20 & .37 & .27 & .24 & .27 & .07 & & & & & \\
\hline \multicolumn{21}{|l|}{ Other variables } \\
\hline [11] Burnout/engagement & 2.95 & 1.21 & .94 & 1.00 & 7.27 & 0.69 & -.35 & -.16 & -.32 & -.20 & -.14 & .01 & -.07 & -.06 & .35 & -.11 & & & & \\
\hline [12] Professional learning time & 4.40 & 1.41 & .90 & 1.00 & 7.00 & -0.55 & .35 & .25 & .38 & .34 & .29 & .13 & .24 & .27 & -.15 & .23 & -.12 & & & \\
\hline [13] Professional learning gains & 5.69 & 1.39 & .95 & 1.00 & 8.00 & -0.58 & .28 & .07 & .35 & .25 & .23 & .03 & .22 & .16 & -.08 & .28 & -.21 & .52 & & \\
\hline [14] Age & 39.00 & 12.05 & - & 23.00 & 94.00 & 1.04 & .11 & -.01 & .05 & -.01 & -.10 & -.13 & -.01 & -.01 & -.20 & -.09 & -.27 & -.12 & -.34 & \\
\hline Gender $(0=$ male; $1=$ female $)$ & 0.49 & 0.50 & - & 0 & 1 & 0.03 & .15 & .04 & .15 & .13 & .14 & .13 & -.02 & .08 & -.03 & .02 & .01 & .07 & .08 & -.16 \\
\hline
\end{tabular}

Achievement goals. To assess researchers' achievement goals, we used the questionnaire developed by Daumiller et al. (2019) for the instructional context in higher education, and adapted it to the research context. We asked the participants to refer their answers exclusively to their research activities using the item stem "In my current research activities, ...". Symmetrical wording was used between approach and avoidance goal classes (e.g., for task approach and task avoidance goals: "... I want to fulfill the different requirements very well" vs. "... I want to avoid fulfilling the different requirements poorly"). There were four items for each type of goal class (example items are included in Table 1); all were answered on Likert-type scales ranging from 1 (do not agree at all) to 8 (agree completely).

Job burnout/engagement. As described before, the majority of international research literature about burnout is based on the approach underlying the Maslach Burnout Inventory (MBI; Maslach, Schaufeli, \& Leiter, 2001). We used a validated German translation of the MBI for general professions (MBI-GS-D; Büssing \& Glaser, 1998), which we slightly modified to accommodate for the academic context. It subsumes (a) emotional exhaustion (e.g., "I feel emotionally exhausted by my work"; 6 items), (b) cynicism (e.g., "I just want to do my job and be left alone"; 5 items), and (c) reduced personal accomplishment (e.g., "I feel good when I have achieved something at work"; 5 items). All items of the third subscale reflect positive engagement and were reversed for the analyses; therefore, high values represent a strongly perceived lack of personal accomplishments. Overall, unfavorable scores on all scales are therefore indicative for burnout, whereas favorable scores are indicative for engagement. The respondents were requested to refer their answers to their current work and to indicate on an 8-point Likert-type scale ranging from 1 (never) to 8 (very often) how often they experienced the presented aspects within the past 6 months. As we were interested in burnout/engagement as a whole, we analyzed it on the overall scale level (see Brenninkmeijer \& van Yperen, 2003), i.e., averaged the three subaspects to a uniform indicator of burnout/engagement (justified by sufficiently large inter-correlations, $\rho=.49-.78){ }^{2}$

Professional learning time. To assess participants' professional learning time, we distinguished between formal and informal learning activities. We first presented examples for both learning activities to ensure that participants understand them adequately. Then, for formal and informal learning separately, the participants were asked to assess the time in hours they spent in the last six months to advance (a) content knowledge (e.g., professional knowledge, knowledge of different scientific discussions), as well as (b) method skills (e.g., literature search, writing, research methods, statistical procedures). To allow for a uniform distribution 
of the data, we used seven categories $(0,1-2,3-5,6-$ $10,11-20,21-40,41+$ hours). We aggregated the answers to these altogether four items by calculating their means (supported by good internal consistencies).

Professional learning gains. As external measures such as competence tests or reports by others are not feasible for research designs as in the current study, we used a self-report based approach to assess participants' professional learning gains. We distinguished between the two learning contents described above and asked participants regarding the last six months with two items each to assess their learning gains in content knowledge (e.g., "To what extent have you increased your professional research knowledge?") and method skills (e.g., "To what extent have you increased your research skills?") on a scale from 1 (not at all) to 8 (very extensively).

Analyses. We conducted confirmatory factor analyses for the structure of the goals, measurement invariance analyses regarding the stability of this structure, and structural equation modeling to yield cross-sectional results regarding the associations with burnout/engagement and professional learning. Missing data $(<2.7 \%$ for each item) was handled using the fullinformation maximum likelihood estimation (FIML) and the EM-algorithm for all analyses (Peugh \& Enders, 2004). All analyses were conducted with Mplus (Muthén \& Muthén, 2017) using the MLR estimator. $\chi^{2}$ and SRMR were used as absolute fit indices, TLI as a relative fit index that also adjusts for parsimony, and RMSEA and CFI as noncentrality-based indices. We used CFI $>.90$, TLI $>.90$, RMSEA $<.10$, and SRMR $<.08$ as cut-off values (see SchermellehEngel, Moosbrugger, \& Müller, 2003). Differences in model fit were evaluated using the differences in CFI and RMSEA (using the common cut-off values of $\triangle \mathrm{CFI}=.01$ and $\triangle \mathrm{RMSEA}=.015$; Chen, 2007).

Confirmatory factor analyses. Regarding the structural questions (H1), we conducted Confirmatory Factor Analyses (CFA). We compared more and less conflated models that subsume or differentiate different achievement goals (e.g., for performance goals, we compared a model with a single factor against models with two factors - differing between approach and avoidance, or appearance and normative goals respectively-as well as a four factor model). Due to the construction of the goal questionnaire (symmetrical formulation of items for approach and avoidance components, which leads to shared method variance), we a priori decided to model correlated errors between the corresponding items (Brown, 2015). To confirm the invariance of this goal structure across different groups of researchers, we conducted multi-group confirmatory factor analyses (MGCFA; further details are presented in the electronic supplement).

Structural equation modeling. In order to analyze the associations between achievement goals and burnout/engagement, professional learning time, and professional learning gains, we estimated a structural equation model (SEM) using latent constructs based on item parcels as indicators (which is preferable to using items as indicators as it reduces the amount of error in complex model estimations; Little, Rhemtulla, Gibson, \& Schoemann, 2013). We used the item-to-construct method, using two parcels for each construct (Little, Cunningham, \& Shahar, 2002) and modeled the effects of all achievement goals on the three dependent variables. Additionally, we modeled correlations between all goals and residual correlations between the dependent variables.

\subsection{Results and Discussion}

Descriptive statistics (Table 3 ) revealed moderate to rather high means for the achievement goals (except work avoidance goals), indicating that they constitute important aspects of researchers' motivations and that researchers frequently pursue multiple goals. In light of Study 1, it is worth noting that mastery/performance avoidance goals also yielded relatively high means (as opposed to the interview setting, in which these goals were articulated less frequently than approach-based goals). Also, nearly the complete theoretical range was attained, and rather large variances were observed, pointing to substantial differences between researchers in the importance of these goals. For task and learning approach goals this variability was slightly restricted due to the high prevalence of these goals in researchers (which was, however, still in an acceptable range, and within normal limits regarding skewness). Taken together, these findings align with the previous interview study and indicate that achievement goals constitute important aspects of university researchers' motivations and that, at the same time, substantial inter-individual differences in the personal importance of different achievement goals exist. This points to the usefulness of Achievement Goal Theory for describing researchers' motivations. Furthermore, the questionnaire-approach appears useful for also capturing the goals that researchers might not spontaneously articulate themselves (mastery/performance avoidance goals).

Structure of university scholars' achievement goals for research. Table 4 summarizes all estimated 
CFA models. For performance goals, we found that distinguishing the goals by approach and avoidance components, or appearance and normative standards described the data better than a one-factor model; however, only an incorporation of both aspects (i.e., a fourfactor model) resulted in an acceptable model fit. These four performance goal classes were moderately to highly correlated $(\rho=.46-.78)$. Similarly, we also found for mastery goals that two-factor-models described the data better than a single factor model, but only a differentiation between all four distinguished mastery based goal classes described the data adequately $(\rho=.47-.79)$. The correlations within mastery and within performance based goals were similarly large as those reported in Daumiller et al. (2019), which is also to be expected as mastery and performance based goals have a shared focus and substantial semantic overlap (see Murayama, Elliot, \& Yamagata, 2011). However, the magnitudes of these correlations imply that each goal class contains significant proportions of unique variance.

Altogether, a model with all theoretically possible 10 goal classes (see Table 1) fit sufficiently to the data- the model fit can be interpreted as good, especially when taking the complexity of the model and the presumably strong cross-loadings into consideration (factor loadings: .56-91, factor correlations: $\rho=-.42$ .78). It can be concluded that the proposed model of achievement goals for research (Table 1) is sensible and that achievement goals for research also need to be differentiated by distinguishing between two components of mastery goals (task, learning), two components of performance goals (appearance, normative), two valence dimensions of these goals (approach, avoidance), and two further relevant goal classes (work avoidance, relational).

Finally, the analyses of measurement invariance (see electronic supplement) indicated that for different groups of researchers, this structure of goals holds

Table 4

Comparison of Hypothesized and Alternative Models in Study 2

\begin{tabular}{|c|c|c|c|c|c|c|c|}
\hline Model & $d f$ & $\chi^{2}$ & $\chi^{2 / d f}$ & CFI & TLI & RMSEA & SRMR \\
\hline \multicolumn{8}{|l|}{ Performance goals } \\
\hline One factor model & 96 & 1815.7 & 18.91 & .73 & .67 & .15 & .06 \\
\hline Approach-avoidance model & 95 & 1063.7 & 11.20 & .85 & .81 & .11 & .08 \\
\hline Appearance-normative model & 95 & 1395.6 & 14.69 & .80 & .75 & .13 & .08 \\
\hline Four factor model & 90 & 417.5 & 4.64 & .95 & .93 & .06 & .04 \\
\hline \multicolumn{8}{|l|}{ Mastery goals } \\
\hline One factor model & 96 & 1443.4 & 15.03 & .66 & .57 & .13 & .13 \\
\hline Approach-avoidance model & 95 & 1030.8 & 10.85 & .76 & .70 & .11 & .12 \\
\hline Task-learning model & 95 & 1306.0 & 13.74 & .69 & .61 & .12 & .11 \\
\hline Four factor model & 90 & 428.1 & 4.75 & .92 & .90 & .07 & .06 \\
\hline \multicolumn{8}{|l|}{ Complete model } \\
\hline Ten goal classes & 679 & 1373.9 & 2.82 & .92 & .91 & .05 & .05 \\
\hline
\end{tabular}

equally, and identical constructs are measured. Although the work of full professors, postdoc staff members, and staff members without a $\mathrm{PhD}$ is rather different, our findings imply that these distinctions between achievement goal classes hold true for the research context in general. This is an important premise that is not self-evident as researchers might understand these goals and respond to the respective items differently based on their academic and professional socialization. Furthermore, we can take this large stability across groups as an indication that although we only investigated German researchers, our findings might also be transferred to other research institutions or different countries.

Associations between goals, job burnout/engagement, and professional learning. Figure 1 shows the SEM estimated to examine the associations between achievement goals, job burnout/engagement, professional learning time, and professional learning gains. This model yielded a good fit to the data $(d f=213$, $\chi^{2}=606.1, \quad$ CFI $=.97, \quad$ TLI $=.95, \quad$ RMSEA $=.05$, SRMR $=.04)$. In line with our expectations, achievement goals were differentially associated with the three variables and explained a substantial amount of their variance $\left(R^{2}=.21-.23\right)$.

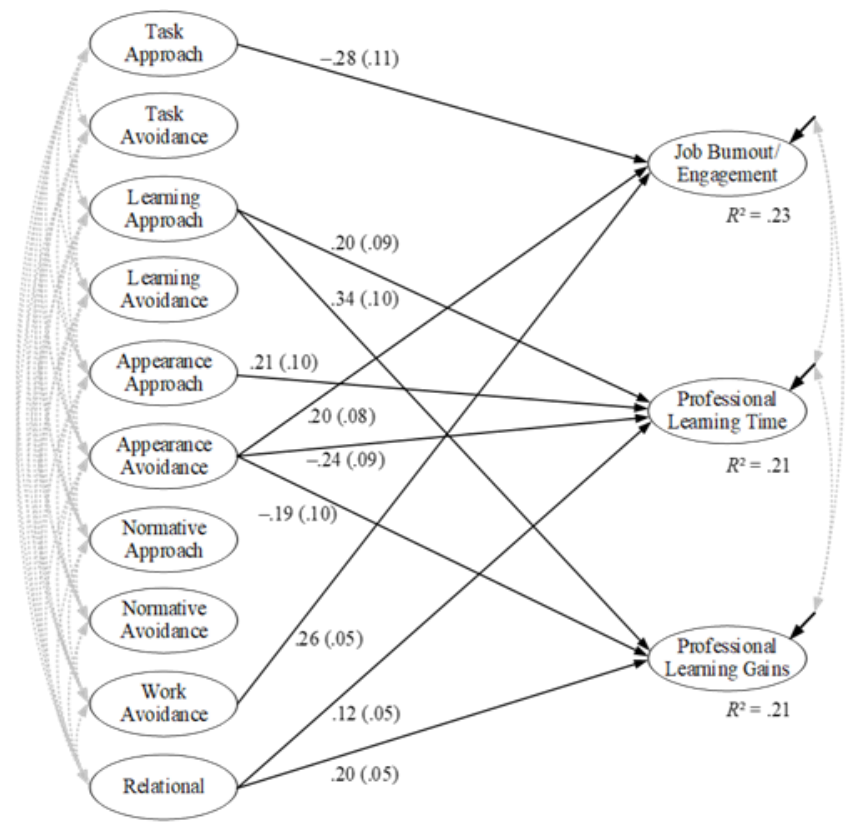

Figure 1. Results of structural equation modeling of the associations between achievement goals and work stress, professional learning time as well as professional learning gains in Study 2 (presented are standardized coefficients and their standard errors). Only significant parameters at $p<.05$ are displayed, all parameters are provided as an electronic supplement (Table S3). Factor loadings and (residual) correlations are not presented for reasons of clarity. 
Specifically, task approach goals were negatively associated with the experience of burnout, and learning approach goals were positively associated with professional learning time and professional learning gains. For mastery avoidance goals, we found no statistically significant associations. For performance based goals, appearance avoidance goals were positively associated with burnout levels and negatively with the two aspects of professional learning, and appearance approach goals were positively associated with professional learning time. ${ }^{3}$ For normative goals, we did not find statistically significant effects regarding burnout/engagement and professional learning. Regarding the two further goal classes, work avoidance goals went along with increased burnout levels, and relational goals were positively associated with professional learning time and professional learning gains.

\section{Study 3}

\subsection{Method}

To address the temporal ordering of these associations (H2), we assessed achievement goals, burnout/engagement, professional learning time, and professional learning gains twice across 6 months and investigated their cross-lagged effects. We sampled the participants from the same fields as in Study 2, and additionally included Romance studies and chemistry.

Participants and procedure. Altogether $471 \mathrm{Ger}-$ man university scholars participated (at T1: 113 full professors, 187 postdoc staff members, 168 staff members without a $\mathrm{PhD} ; 245$ males, 226 females; mean age 37.2 years, $S D=10.9)^{4}$. To recruit them, we sent out postcards to a nationwide representative gross sample (we did not contact scholars who had already participated in Study 2). On the postcards, we asked for participation in our study and posed four short questions which we subsequently used to confirm that our final sample was not systematically distorted regarding participants' demographic composition and their goals (the questions were answered also by those researchers who states that did not want to participate in our study). The participants that we recruited using this procedure subsequently received two paper-and-pencil questionnaires, 6 months apart (52\% of questionnaires were sent back) that were matched using an anonymous code word generated by the participants. Their participation was encouraged by use of incentives.

Measures. We used the same scales as in Study 2 to assess participants' achievement goals, professional learning time, professional learning gains, and burnout/engagement on both occasions. ${ }^{5}$ Regarding learning and burnout, we asked the participants to refer all their answers to the last 6 months. Table 5 shows the internal consistencies of all scales.

Analyses. There were very few missing values $(<3.6 \%$ for each item) which were dealt with the FIML estimator and the EM-algorithm for all analyses (Peugh $\&$ Enders, 2004). Unless otherwise noted, we used the same procedures as in Study 2 (using MLR as estimator, Mplus as software, and CFI, TLI, RMSEA, SRMR as fit indices).

Measurement invariance over time. As a main prerequisite for the analysis of longitudinal data is measurement invariance of the assessed constructs over time, we conducted measurement invariance analyses. We used an analogous procedure as in Study 2 (see electronic supplement) and estimated measurement invariance for a model containing all variables as used in the cross-lagged panel models in the next type of analysis.

Cross-lagged panel models. To analyze the effects of goals on outcome variables, we estimated three cross-lagged panel models. Each model contained, for $\mathrm{T} 1$ and $\mathrm{T} 2$, all ten goals and either burnout/engagement, professional learning time, or professional learning gains. We estimated all variables as latent variables using item parcels like in Study 2 and regressed all T2variables on all $\mathrm{T} 1$ variables. We were primarily interested in the effects between goals on the one hand and burnout/engagement, professional learning time, and professional learning gains on the other hand. As these effects might, in part, be distorted due to the inclusion of the effects between goals, we conducted additional analyses: For each goal that yielded a statistically significant relationship with burnout/engagement, professional learning time, or professional learning gains in the comprehensive model, we calculated a "simple" cross-lagged model, containing only the respective goal and the respective external variable at T1 and T2.

\subsection{Results and Discussion}

We observed quite similar descriptive statistics as in Study 2 (see Table 5). As before, the means and variances point to achievement goals constituting important aspects of university researchers' motivations with substantial inter-individual differences. Also, in 
Table 5

Descriptive Statistics and Latent Correlations Between Achievement Goals, Job Burnout/Engagement, and Professional Learning, in Study 3

\begin{tabular}{|c|c|c|c|c|c|c|c|c|c|c|c|c|c|c|c|}
\hline & \multicolumn{4}{|c|}{ Descriptives T1 } & \multicolumn{4}{|c|}{ Descriptives T2 } & \multirow[b]{2}{*}{$r_{12}$} & \multicolumn{3}{|c|}{ Correlations T1 } & \multicolumn{3}{|c|}{ Correlations T2 } \\
\hline & $M$ & $S D$ & $\omega$ & Skew & $M$ & $S D$ & $\omega$ & Skew & & 1 & 2 & 3 & 1 & 2 & 3 \\
\hline \multicolumn{16}{|l|}{ Mastery goals } \\
\hline Task approach & 7.24 & 0.84 & .87 & -1.55 & 7.26 & 0.91 & .87 & -1.53 & .68 & -.04 & .20 & .14 & .05 & .24 & .14 \\
\hline Task avoidance & 7.14 & 1.34 & .93 & -2.36 & 7.03 & 1.42 & .94 & -2.28 & .55 & .01 & .10 & .11 & .08 & .15 & .15 \\
\hline Learning approach & 7.35 & 0.75 & .88 & -1.34 & 7.16 & 0.91 & .90 & -1.50 & .62 & -.12 & .26 & .31 & -.13 & .27 & .25 \\
\hline Learning avoidance & 6.79 & 1.45 & .90 & -1.16 & 6.72 & 1.42 & .92 & -1.50 & .50 & .01 & .05 & .18 & -.02 & .29 & .24 \\
\hline \multicolumn{16}{|l|}{ Performance goals } \\
\hline Appearance approach & 6.25 & 1.43 & .92 & -1.21 & 6.10 & 1.42 & .93 & 0.96 & .71 & .01 & .10 & .13 & .03 & .21 & .14 \\
\hline Appearance avoidance & 6.33 & 1.74 & .96 & -1.28 & 6.27 & 1.73 & .96 & -1.15 & .67 & .08 & -.02 & .05 & .07 & .07 & .03 \\
\hline Normative approach & 4.09 & 1.97 & .95 & 0.14 & 4.17 & 1.96 & .97 & 0.03 & .71 & .07 & .08 & .16 & .11 & .11 & .15 \\
\hline Normative avoidance & 5.62 & 1.98 & .96 & -0.71 & 5.69 & 1.95 & .97 & -0.72 & .65 & .06 & -.04 & .06 & .11 & .18 & .14 \\
\hline \multicolumn{16}{|l|}{ Further goals } \\
\hline Work avoidance & 2.08 & 1.32 & .92 & 1.72 & 2.23 & 1.51 & .95 & 1.55 & .64 & .18 & -.23 & -.11 & .26 & -.16 & -.04 \\
\hline Relational & 5.59 & 1.57 & .85 & -0.81 & 5.48 & 1.50 & .84 & -0.65 & .59 & .03 & .12 & .15 & .11 & .04 & .18 \\
\hline \multicolumn{16}{|l|}{ Other variables } \\
\hline [1] Burnout/engagement & 2.91 & 1.07 & .92 & 0.81 & 3.00 & 1.15 & .93 & 0.84 & .78 & & & & & & \\
\hline [2] Professional learning time & 3.70 & 1.30 & .88 & 0.22 & 3.60 & 1.22 & .81 & 0.44 & .35 & -.08 & & & -.09 & & \\
\hline [3] Professional learning gains & 5.73 & 1.42 & .88 & -0.66 & 5.63 & 1.51 & .91 & -0.68 & .53 & -.08 & .69 & & -.08 & .60 & \\
\hline Age & 38.17 & 10.92 & - & 0.87 & 38.67 & 11.02 & - & 0.86 & - & -.13 & -.20 & -.12 & -.19 & -.13 & -.12 \\
\hline Gender $(0=$ male; $1=$ female $)$ & 0.48 & 0.50 & - & 0.08 & 0.48 & 0.50 & - & 0.08 & - & -.02 & -.02 & .06 & -.02 & .05 & .07 \\
\hline
\end{tabular}

Note. $N=471 . r_{12}$ shows manifest auto-correlations for each variable between the two measurement time points. The two last blocks show latent correlations between goals, job burnout/engagement, and professional learning at T1, and T2 respectively. They were estimated using a measurement model containing all latent variables with item parcels for T1 and T2 $\left(d f=268, \chi^{2}<677.1, \mathrm{CFI}>.95, \mathrm{TLI}>.93, \mathrm{RMSEA}<.06\right.$, SRMR $\left.<.05\right)$. Statistically significant coefficients $(p<.05)$ are in boldface. A complete correlation matrix including all variables for T1 and T2 is provided in an electronic supplement (Table S4).

line with the structural results from Study 2, an overall model distinguishing between all ten goals fitted well at both measurement points $\left(d f=679, \chi^{2}<1504.3\right.$, CFI $>.93$, TLI $>.92, \quad$ RMSEA $<.05, \quad$ SRMR $<.04)$, which confirms the finding from Study 2 that the proposed goal classes describe the achievement goals for research well (H1). Overall, the descriptive statistics were very similar for both studies, highlighting that fundamental aspects of the nature of the goals could be replicated.

Additionally, we observed moderate stability of goals over time $(r=.50-.71)$ with mastery-based goals being descriptively slightly less stable than performance-based goals, having slightly more variability in professional learning time and gains over time $(r=.35$ 53), and a rather strong temporal stability of burnout/engagement levels $(r=.78){ }^{6}$ The stability of achievement goals for research over six months was in a similar range to that typically observed when investigating the stability of achievement goals of other populations over time (e.g., Janke \& Dickhäuser, 2018; Praetorius et al., 2014; Senko, Hulleman, \&
Harackiewicz, 2011), indicating that goals contain temporally stable as well as variable aspects (Jagacinski, Kumar, Boe, Lam, \& Miller, 2010; Tuominen-Soini, Salmela-Aro, \& Niemivirta, 2011).

We found complete measurement invariance over time for the model containing all variables as used in the cross-lagged panel models which consitutes an essential prerequisite for the following analyses (see Table $\mathrm{S} 2$ in the electronic supplement).

Results of the cross-lagged panel models are presented in Figure 2. In line with the results regarding the stability of the measured constructs, we observed strong autoregressive effects for burnout/engagement, moderate ones for professional learning gains, and rather small effects for professional learning time. Overall, the results of these analyses were similar to the associations found in Study 2 and expanded them by additionally facilitating an understanding of the directions of these effects (H2).

Cross-lagged effects between goals and job burnout/engagement. Specifically, regarding the effects between goals and burnout/engagement (Model a), normative avoidance goals at T1 emerged as a (positive) predictor of an increase in burnout levels from $\mathrm{T} 1$ to T2. Simultaneously, relative to other researchers, 
higher levels of burnout at T1 were associated with a reduction of task approach and learning approach, and an increase in work avoidance goals over the 6 months. These findings match the associations reported in Study 2 and are in line with (the mostly cross-sectional) results found in other populations, such as school teachers (e.g., Retelsdorf et al., 2010). It is worth noting that Retelsdorf et al. (2010) reported associations between mastery goals and burnout/engagement using a crosssectional design, but not in a longitudinal design, in which the effects from goals at the beginning of the year on burnout/engagement at the end of the year were investigated (but no effects from goals on burnout/engagement). Our findings highlight that effects from burnout/engagement on the goals also exist. In fact, we found more effects from burnout/engagement on changes in goals than the other way around - with a reduction of mastery approach and an increase in work avoidance goal pursuit after experiencing high burnout levels.

Apart from understanding the nexuses of researchers' motivations, these results are important to expand knowledge of the general mechanisms between goals and burnout/engagement at work. It seems to be the case that researchers reduce favorable (but resource-intensive) achievement goals, such as task approach and learning approach goals as a result of high burnout experiences. This might constitute an adaptive coping strategy, in line with recommendations by Gmelch (1993), who suggests stressed researchers to change their prioritized goals. As strong learning approach and task approach goals are resource-intensive to realize, it might be functional to tackle them first in stressful and exhausting situations.

Our results also presented evidence that an adoption of (typically unfavorable) work avoidance goals might also be due to high burnout levels. This could be a convenient short-term strategy to handle high work-pressure, but may not work very well in the long run as constantly avoiding work could increase burning out over time (due to an accumulation of important tasks, missed deadlines, insufficient performance, etc.). Future research might profit from more complex longitudinal designs to thoroughly understand how exactly these two constructs are intertwined. Lastly, regarding performance avoidance goals, Study 3 indicated that especially normative strivings are associated with the development of burnout (see Friedman, 2000). As we did not find the same results in Study 2, these findings should be interpreted with caution and followed up on in future research.
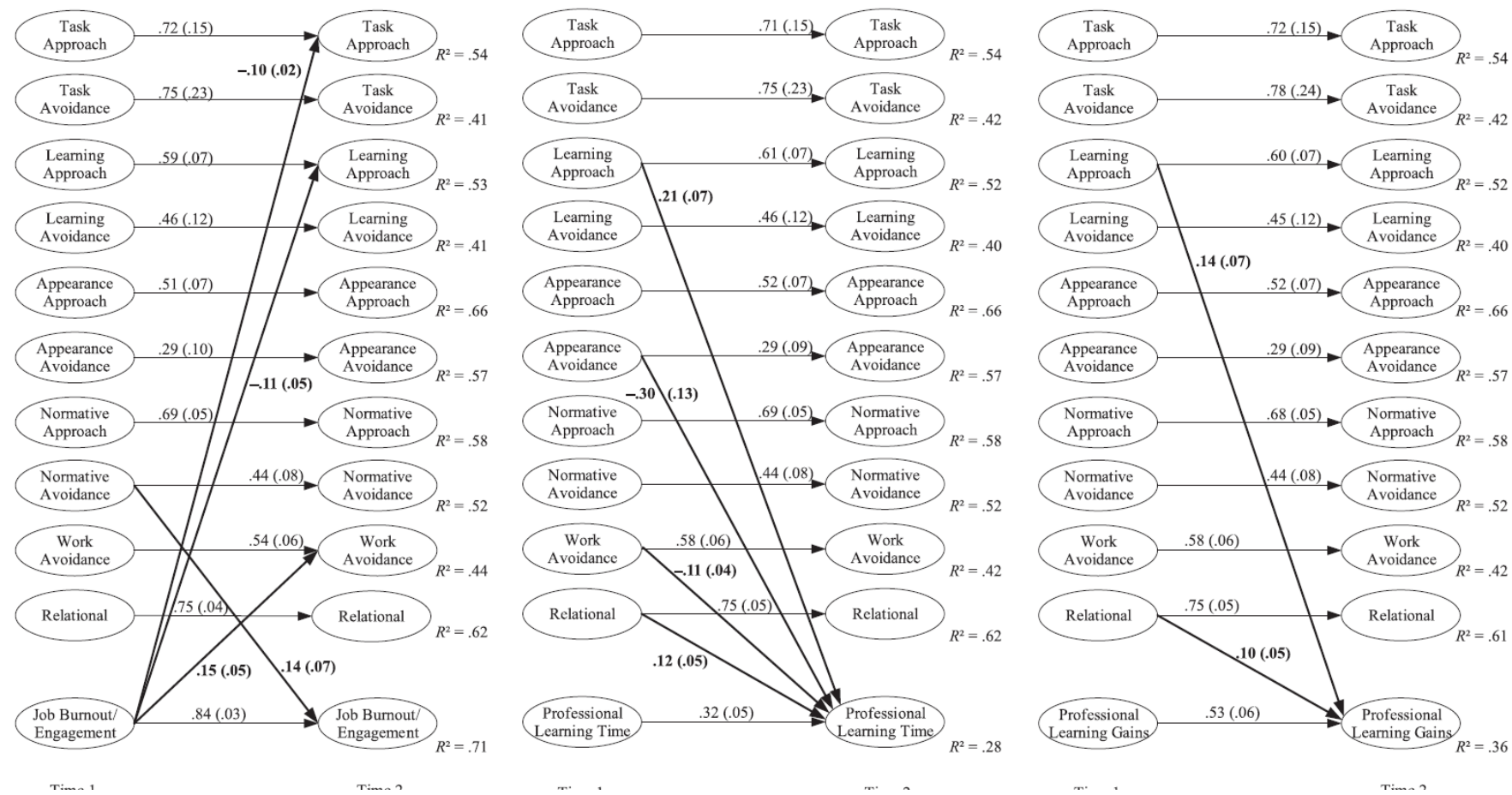

Figure 2. Results of cross-lagged analyses for achievement goals and (a) work stress, (b) professional learning time, and (c) professional learning gains in Study 3 (presented are standardized coefficients and their standard errors in brackets). Only significant parameters at $p$ $<.05$ are displayed, all parameters are provided as an electronic supplement (Table S5). Factor loadings, residuals, and (residual) correlations are not presented for reasons of clarity. 
Cross-lagged effects between goals and professional learning. Concerning researchers' professional learning (Model b), we found clear evidence for effects of goals on professional learning over time: learning approach goals and relational goals at $\mathrm{T} 1$ were positive predictors of an increase in professional learning time, while appearance avoidance and work-avoidance goals were negative predictors. In contrast to the results found for burnout/engagement and in line with our expectations, we only found effects from goals on learning time, while learning time at $\mathrm{T} 1$ did not significantly predict changes in goals. For professional learning gains (Model c), we found similar effects for learning approach and relational goals that were positive predictors for learning gains over time, while no other effects were statistically significant.

The finding that learning approach goals, but not task approach goals, are associated with an increase in professional learning time is in line with our expectations. This confirms the well-documented significance of learning goals for personal learning (Payne et al., 2007) and expands previous research by showing that in occupational settings - which, of course conducting research in universities is - task and learning goals might work differently. For students, completing tasks directly implies learning as most of their tasks at school are learning related. Because of that, task and learning goals might similarly be associated with learning for students. However, in general occupational settings, a multitude of different tasks exist, and only a small part of them is deliberately directed at personal learning. Therefore, it seems reasonable that learning goals chiefly matter for personal learning, while task goals might be more relevant for other aspects of their professional behavior, such as their actual performance (see Mascret, Elliot, \& Cury, 2015). Thus, a clear separation of task and learning goals appears crucial, especially when investigating achievement goals at work.

Apart from the positive effects for learning approach goals, we did not find evidence regarding the importance of learning avoidance goals. This is in line with the mixed nature of this type of goal (see Elliot et al., 2011), with a favorable focus on learning, but a negatively connoted general attitude due to their valence (that might hinder effective learning).

For performance goals, we found, in line with our expectations and previous research on various populations (e.g., Nitsche, Dickhäuser, Dresel, et al., 2013; Payne et al., 2007; Pintrich, 2000), negative results for performance avoidance goals, but no (interpretable) effects for performance approach goals. We expanded previous research by showing that, at least for university scholars, appearance and normative aspects should be distinguished, as only appearance avoidance goals mattered for professional learning. Together with the findings by Daumiller et al. (2019) regarding university scholars' achievement goals for teaching and the results for normative avoidance goals and researchers' burnout/engagement, this could indicate that appearance and normative goals might span up different motivational systems that are associated with different sets of processes: appearance goals might be more relevant for actual behavior (e.g., learning behaviors, teaching practices), whereas normative goals might matter more for their experiences and appraisals of their current situations (e.g., emotions, burnout/engagement; see also the effects for normative avoidance goals on burnout/engagement described above).

For work avoidance goals, we found partial evidence in line with their expected detrimental effects on professional learning. It might be the case that in the research domain, professional learning gains can still be achieved when having moderate levels of work avoidance goals, for instance, using effective reprioritization or focusing, while actual professional learning time is also reduced when moderately pursuing such goals (this makes sense, as professional learning is, although very important, often not highly prioritized, as opposed to important deadlines, manuscript submissions, etc.). In work settings, work avoidance goals and professional learning have mainly been studied regarding learning time but not learning gains (Nitsche, Dickhäuser, Dresel, et al., 2013; Nitsche, Dickhäuser, Fasching, et al., 2013). Our findings highlight that this line of research might profit from including learning gains, and/or further variables looking at the quality of learning (such as attentiveness, learning strategies, etc. when learning) in order to explain differences in professional learning.

Lastly, for relational goals, we found the expected positive effects on professional learning time and professional learning gains. As far as we are aware, this association has not been investigated in other populations (Butler, 2012; Butler \& Shibaz, 2014). Our results can be taken as an initial indication that strong strivings to interact with colleagues in the research context might also lead individuals to pursue situations where they can attain these goals more strongly and in doing so also improve their competencies (e.g., consulting colleagues for help or attending workshops) .

Taken together, this third study documented the importance of distinguishing between the different types of achievement goals that were associated differently 
with the dynamics of burnout/engagement and learning, and helped to facilitate a better understanding of their importance in the research domain.

\section{General Discussion}

The main aim and innovation of present work was to apply a well-established motivational framework to explain behavior and experiences of an under researched population. We expanded the sparse evidence on researchers' motivations and investigated their connection with burnout/engagement and professional learning at work. Specifically, we tested an AGT approach and consistently confirmed over three studies that it is a suitable and powerful framework for describing researchers' motivations. We investigated the prevalence and structure of researchers' achievement goals and analyzed with multiple designs how these goals are related to burnout/engagement and professional learning. Strengths of the present work include the innovative focus on university researchers whose productivity is essential for societal progress, the use of a preceding interview study to analyze the actual prevalence of researchers' achievement goals, followed by a systematic transfer and confirmation of an achievement goal framework, the use of different research designs that also included a longtail study as well as thorough, multivariate analyses on a latent level.

Our results show that university scholars pursue a multitude of personal goals for research with large inter-individual differences. It is noteworthy that in Study 1 only a few goals could not be classified as achievement goals, which supports the notion that AGT provides a suitable approach for describing researchers' goals. As the majority of all articulated goals could be classified as one of the ten achievement goals examined in this work, it can be concluded that these goals are prevalent and central to research motivations. Our findings document that an AGT framework appears sensible and powerful in describing motivational differences between researchers and for facilitating research on this important population.

Furthermore, we tested an achievement goal framework that followed the finer differentiations and goal classes proposed in the literature (see Butler, 2012; Elliot, 2005; Elliot et al., 2011; Grant \& Dweck, 2003; Hulleman et al., 2010) and distinguished between two components of mastery goals (task, learning), two components of performance goals (appearance, normative), two valence dimensions of these goals (approach, avoidance), and work avoidance and relational goals as further relevant goal classes (Daumiller et al., 2019).
We found that university scholars' achievement goals for research were adequately described by this framework (confirmation of Hypothesis H1). Particularly, we found that the distinguished goals were differentially associated with the experiences and behaviors of researchers at work that we addressed in our studies. Exceptions were only task avoidance and performance approach goals (however, we had no expectations for these goals regarding the studied variables, and can presume that at least performance approach goals should be highly relevant for performance at work). Similar to the teaching domain, our results indicate that for university scholars it is crucial to disentangle task goals (which might be more relevant for performance at work) and learning goals (which might be more relevant for deliberate professional learning at work) as separate aspects of mastery goals. Regarding performance goals, appearance goals (which might matter for actual behavior and performance) and normative goals (which might be more important for emotional experiences and appraisals) should clearly be distinguished theoretically. It should be noted that this does not imply that all goals need to always be assessed when analyzing researchers' motivations. Instead, depending on the research question at hand, the goals in question should be carefully selected, clearly defined and labeled, and stringently operationalized (see also Hulleman, et al., 2010). We also found that work avoidance and relational goals constituted important aims that were pursued by the researchers in their everyday achievement situations and were relevant for predicting burnout/engagement and professional learning of researchers at work. Although the inclusion of these typically noncompetence-based goals is controversially discussed in the achievement goal literature (e.g., Elliot \& Hulleman, 2017; Murayama et al., 2012), we consider this a strong argument for including them to understand researchers' goal pursuits in achievement situations. Future research could profit from looking at the mechanisms following these goals in more detail, e.g., by investigating how relational goals translate into high learning gains and how they can help to attain the satisfaction of the psychological need for relatedness (see Lechuga \& Lechuga, 2012; Stupnisky et al., 2015; Stupnisky et al., 2017; Stupnisky et al., 2018), and whether moderate levels of work avoidance goals might not necessarily be detrimental to professional learning.

An important question following the separability of these achievement goals and their possibly different relevance for experiences and behavior of university scholars concerns the generalizability of these findings. 
We found that the structure of achievement goals was robust across different status groups of researchers (measurement invariance). Together with the results by Daumiller et al. (2019), we consider these findings as evidence that the proposed distinction of achievement goals works equally well for different types of scholars, and - although we only surveyed German university scholars - could be transferred to other countries or university systems. On a larger scale concerning generalizability, it seems plausible that some of the distinctions made (e.g., for mastery goals) might be transferable to other occupational settings, but not to students (where task and learning goals possibly have a more similar function); future research should follow up on this claim.

Furthermore, our findings contribute to an understanding of the links between research motivations, burnout/engagement, and professional learning, by confirming most of our expectations and elaborating on the directions of these effects (largely confirming Hypothesis H2). We found strong effects in Study2, which, although reduced in their sizes, were robust, also in a longitudinal cross-lagged design over 6 months (Study 3 ). Particularly normative performance avoidance goals seem to matter for the development of burnout, which in turn causes unfavorable goal setting processes (less task and learning approach, more work avoidance goals), while learning approach and relational goals can be considered to be highly functional for professional learning. These findings are especially important as researchers' effective functioning is strongly influenced by their burnout levels and professional learning (see Hodgson, 2016). These two aspects were only slightly interrelated in our studies and are functionally directed at different time perspectives (job burnout/engagement mattering for whether one's full competencies can be used/actualized in a current situation, while professional learning is relevant for the development of one's competencies over time). Nevertheless, an interesting perspective might be to examine their relation in more detail based on the findings presented here - especially by investigating whether goals mediate the relation between burnout/engagement and impaired professional learning, or possibly whether burnout/engagement moderates the effect of learning goals on professional learning).

The importance of these two aspects for optimal functioning of researchers was also underlined in our studies as we observed a high variation in professional learning (pointing to important differences between researchers and over time) and relatively high burnout levels that were rather stable over time. This is in line with the high burnout levels reported in university faculty in previous works (e.g., Blix et al., 1994; Lackritz, 2004; Singh et al., 1998). As troubling signs for higher education research can currently be seen (e.g., in the US, a decline in research productivity has been reported; Hill, Rapoport, Lehming, \& Bell, 2007; Javitz et al., 2010; Litwin, 2014) and institutionalized approaches to support individual researchers seem to have little effect, it is especially important to understand the driving forces of individual researchers, in order to support them in their experiences and behaviors at work (see Stupnisky, et al., 2017, for a similar argument). The present work underlined the importance of researchers' achievement goals that can influence job burnout/engagement (while also being adapted depending on current burnout/engagement levels) and systematically predict learning time and learning gains as aspects of their professional learning. While this constitutes an important contribution, future research should also include other variables, e.g., by investigating how goals translate into actual performance at work. Another research direction might entail considering features of the achievement context that could moderate the effects of the goals (e.g., researchers' learning goals might especially lead to increased professional learning in work contexts that promote and support professional development).

Lastly, our findings show a moderate stability of goals over six months, implying that they contain a substantial portion of stable, personal fractions while at the same time also being variable (Bürger \& Schmitt, 2017; Corker, Donnellan, \& Bowles, 2013; Fryer \& Elliot, 2007; Praetorius et al., 2014). This affirms that the achievement goal approach is sensible to describe actual differences between researchers in their motivations, while enabling practical implications (based on their goals being able to change).

\subsection{Limitations and Practical Implications}

Although the current study has many strengths, there are also limitations that need to be considered when interpreting the results. Firstly, we only used selfreported data. While this is adequate for the assessment of goals and burnout/engagement, researchers' professional learning might have also been assessed by other means (although especially informal learning activities and learning gains across different learning activities used would be difficult to capture, and we specifically employed a highly differentiated instrument to allow for precise answers). This implies that the results re- 
garding professional learning need to be carefully interpreted and followed up on with more research (e.g., by analyzing the effect of goals for learning gains in a specific workshop). Secondly, due to the recruitment strategy (voluntary participation), it could be the case that those with favorable motivations and a strong sense of professional identity are overrepresented in our samples. This is primarily relevant for adequately interpreting the overall means, however the associations between achievement goals and the other variables could also be affected by this (e.g., professional identity could act as a hidden moderator). Third, the studies at hand were variable-focused. As individuals are expected to pursue multiple goals simultaneously that can span up different motivational systems due to their interplay (see Wormington \& Linnenbrink-Garcia, 2017, for an overview), future research could profit from person-centered methodologies (such as profile analyses) that explicitly allow for the investigation of the interplay between different achievement goals and its relevance beyond the main effects of the individual achievement goals. Finally, we only investigated scholars from German universities. As such, we cannot be sure to what extent these findings can be transferred to other research institutes; however, the generalizable goal content observed in Study 1 and the measurement invariance analyses might serve as an initial hint for the generalizability of the findings. This should be followed up on with international samples and different institutional types.

Although the current work was the first of its kind to investigate the achievement goals of university scholars for research, first practical implications can already be drawn. Professional development of university scholars and arrangements of contextual features should focus on developing and enhancing learning goals (Urdan \& Turner, 2005) and possibly task goals, and also support researchers in pursuing these goals under stressful and exhausting situations. Simultaneously, performance avoidance goals should be reduced. When stressed and exhausted, it might be beneficial to tackle normative avoidance goals first, but appearance avoidance goals should also be considered. These detrimental goals could be reduced by framing and construing professional learning as non-competitive and with a constructive error-climate that permits errors and fosters learning from them, while encouraging innovation (see also Järvinen, 2017). Lastly, relational goals should not be regarded as unimportant. Instead, research meetings, workshops, and informal counseling might actively be encouraged to support both relational goals and professional learning. Regarding these practical implications, AGT offers a useful framework as it also describes how different achievement goals are made salient through features of the surrounding context (achievement goal structures, Ames, 1992; Bardach, Oczlon, Pietschnig, \& Lüftenegger, 2020; Kaplan et al., 2002). For researchers, relevant contexts might include the specific lab they work in, their department and institution, as well as their research community in general. Identifying contextual features therein (e.g., degree of social comparison in evaluations) that enhance or undermine adaptive goal pursuit can therefore be considered an important research direction for enabling further practical directions to support researchers' goal pursuit in an adaptive way.

Finally, practical value also lies in the goal measure rooted in the achievement goal framework, which was transferred and confirmed for the research context in the present work. Our studies documented that this measurement instrument taps into constructs that are actually prevalent for researchers (as seen in the results of the interview study on the psychological foci and orientations of the articulated goals). Furthermore, the items correspond to the proposed theoretical framework, while theory-compliant associations with other variables were evident in both quantitative studies. This evidence based on the content of the measure, its internal structure, and its relationships with other measures, points to the validity of the interpretation of the scores measured with this instrument (AERA, APA, \& NCMEA, 2014). Furthermore, the measure portrayed good psychometric properties, similar descriptive results across both quantitative studies, and worked equally well for different groups of respondents and over time. This additionally underlines the usefulness of this measure along with the achievement goal approach for describing relevant motivational characteristics that are suitable to explain differences between individual researchers (as also seen in the predictive power of the goals).

\subsection{Conclusion}

Overall, the present work expands the sparse research on the motivation of researchers and points to the appropriateness and the merits of an achievement goal approach. Achievement goals for research are pursued, prevalent, considered important, and are suitable to describe differences between researchers' motivations. They should be examined in a differentiated manner by distinguishing between two components of mas- 
tery goals (task, learning), two components of performance goals (appearance, normative), two valence dimensions of these goals (approach, avoidance), and two further relevant goal classes (work avoidance, relational). This structure being invariant across different academic status groups points to its generalizability. Lastly, these goals mattered for researchers' burnout/engagement and professional learning at work, which contributes to understanding and supporting optimal functioning of this important population. The present work can be considered important groundwork to facilitate future research (i.e., "me-search") on this important and previously under-investigated population.

\section{References}

American Educational Research Association, American Psychological Association, \& National Council on Measurement in Education. (2014). Standards for Educational and Psychological Testing. Washington, DC: AERA.

Ames, C. (1992). Classrooms: Goals, structures, and student motivation. Journal of Educational Psychology, 84,261-271. doi:10.1037/0022-0663.84.3.261

Baldwin, T. T., \& Ford, J. K. (1988). Transfer of training: A review and directions for future research. Personnel Psychology, 41, 63 -105. doi:10.1111/j.17446570.1988.tb00632.x

Bailey, J. G. (1999). Academics' motivation and self-efficacy for teaching and research. Higher Education Research \& Development, 18, 343-359. doi:10.1080/0729436990180305

Bardach, L., Oczlon, S., Pietschnig, J., \& Lüftenegger M. (2020). Has achievement goal theory been right? A meta-analysis of the relation between goal structures and personal achievement goals. Advanced online publication. Journal of Educational Psychology. doi:10.1037/edu0000419

Barkhuizen, N., Rothmann, S., \& Van De Vijver, F. J. (2014). Burnout and work engagement of academics in higher education institutions: Effects of dispositional optimism. Stress and Health, 30, 322 -332. doi: $10.1002 /$ smi. 2520

Bentley, P. J., \& Kyvik, S. (2013). Individual differences in faculty research time allocations across 13 countries. Research in Higher Education, 54, 329-348. doi:10.1007/s11162-012-9273-4

Bland, C. J., Center, B. A., Finstad, D. A., Risbey, K. R., \& Staples, J. G. (2005). A theoretical, practical, predictive model of faculty and department research productivity. Academic Medicine, 80(3), 225-237.

Blix, A. G., Cruise, R. J., Mitchell, B. M., \& Blix, G. G. (1994). Occupational stress among university teachers. Educational Research, 36, 157-169. doi:10.1080/0013188940360205
Brenninkmeijer, V. \& van Yperen, N. (2003). How to conduct research on burnout. Occupational and Environmental Medicine, 60, 16-20. doi:10.1136/oem.60.suppl_1.i16

Brophy, J. (2005). Goal theorists should move on from performance goals. Educational Psychologist, 40, 167-176. doi: $10.1207 / \mathrm{s} 15326985 \mathrm{ep} 4003 \_3$

Brown, T. A. (2015). Confirmatory factor analysis for applied research. New York, NY: Guilford.

Bürger, K., \& Schmitt, M. (2017). Students' multiple state goals as a function of appraisals, trait goals, and their interactions. Contemporary Educational Psychology, 51, 464-481. doi:10.1016/j.cedpsych.2017.09.006

Büssing, A. \& Glaser, J. (1998). Managerial stress und burnout. A collaborative international study (CISMS). Munich: TUM. Retrieved from http://www.psy.wi.tum.de/LS-Berichte/Bericht-44.pdf

Butler, R. (2007). Teachers' achievement goal orientations and associations with teachers' help-seeking. Journal of Educational Psychology, 99, 241-252. doi:10.1037/0022-0663.99.2.241

Butler, R. (2012). Striving to connect: Extending an achievement goal approach to teacher motivation to include relational goals for teaching. Journal of Educational Psychology, 104, 726-742. doi: $10.1037 / \mathrm{a} 0028613$

Butler, R., \& Shibaz, L. (2014). Striving to connect and striving to learn. International Journal of Educational Research, 65, 41-53. doi:10.1016/j.ijer.2013.09.006

Cannon-Bowers, J. A., Salas, E., Tannenbaum, S. I., \& Mathieu, J. E. (1995). Toward theoretically based principles of training effectiveness: A model and initial empirical investigation. Military Psychology, 7, 141-164. doi:10.1207/s15327876mp0703_1

Chen, F. (2007). Sensitivity of goodness of fit indexes to lack of measurement invariance Structural Equation Modeling, 14, 464-504. doi:10.1080/10705510701301834

Chiaburu, D. S., \& Marinova, S. V. (2005). What predicts skill transfer. International Journal of Training and Development, 9, 110-123.

doi:10.1111/j.1468-2419.2005.00225.x

Colquitt, J. A., LePine, J. A., \& Noe, R. A. (2000). Toward an integrative theory of training motivation: A meta-analytic path analysis of 20 years of research. Journal of Applied Psychology, 85, 678-707. doi:10.1037//00219010.g5.5.678

Corker, K. S., Donnellan, M. B., \& Bowles, R. P. (2013). The development of achievement goals throughout college. Personality and Social Psychology Bulletin, 39, 1404-1417. doi:10.1177/0146167213494243

Daumiller, M., Dickhäuser, O., \& Dresel, M. (2019). University instructors' achievement goals for teaching. Journal of Educational Psychology, 111, 131-148. doi:10.1037/edu0000271 
Daumiller, M., Grassinger, R., Dickhäuser, O., \& Dresel, M. (2016). Structure and relationships of university instructors' achievement goals. Frontiers in Psychology, 7. doi:10.3389/fpsyg.2016.00375

DeShon, R. P., \& Gillespie, J. Z. (2005). A motivated action theory account of goal orientation. Journal of Applied Psychology, 90, 1096-1127. doi:10.1037/00219010.90.6.1096

Dowson, M. \&McInerney, D. M. (2001). Psychological parameters of students' social and work avoidance goals: A qualitative investigation. Journal of Educational Psychology, 93, 35-42. doi:10.1037/0022-0663.93.1.35

Dweck, C. S. (1986). Motivational processes affecting learning. American Psychologist, 41, 1040-1048. doi:10.1037//0003-066x.41.10.1040

Elliot, A. J. (1999). Approach and avoidance motivation and achievement goals. Educational Psychology, 34, 169-189. doi:10.1207/s15326985ep3403_3

Elliot, A. J. (2005). A conceptual history of the achievement goal construct. In A. J. Elliot \& C. S. Dweck (Eds.), Handbook of competence and motivation (pp. 52-72). New York, NY: Guildford.

Elliot, A. J., \& Harackiewicz, J. M. (1996). Approach and avoidance achievement goals and intrinsic motivation: A mediational analysis. Journal of Personality and Social Psychology, 70, 461-475. doi:10.1037//00223514.70.3.461

Elliot, A. J., \& Hulleman, C. S. (2017). Achievement goals. In A. Elliot, C. Dweck, \& D. Yeager (Eds.), Handbook of competence and motivation: Theory and application ( $2^{\text {nd }}$ ed.; pp. 43-60). New York, NY: Guilford.

Elliot, A. J., \& McGregor, H. A. (2001). A $2 \times 2$ achievement goal framework. Journal of Personality and Social Psychology, 80, 501-519. doi:10.1037/00223514.80.3.501

Elliot, A. J., Murayama, K., \& Pekrun, R. (2011). A 3 x 2 achievement goal model. Journal of Educational Psychology, 103, 632-648. doi:10.1037/a0023952

Evans, L. (2011). What research administrators need to know about researcher development: Towards a new conceptual model. Journal of Research Administration, 42, 15-37. Retrieved from http://files.eric.ed.gov/fulltext/EJ954989.pdf

Folkman, S., Lazarus, R. S., Dunkel-Schetter, C., DeLongis, A., \& Gruen, R. J. (1986). Dynamics of a stressful encounter: Cognitive appraisal, coping, and encounter outcomes. Journal of Personality and Social Psychology, 50, 992-1003. doi:10.1037/0022-3514.50.5.992

Ford, M. (1992). Human motivation: Goals, emotions, and personal agency beliefs. Newbury Park, CA: Sage.

Freudenberger, H. J. (1974). Staff burn-out. Journal of Social Issues, 30, 159-165. doi:0.1111/j.15404560.1974.tb00706.x

Friedman, I. A. (2000). Burnout in teachers: Shattered dreams of impeccable professional performance. Journal of Clinical Psychology, 56, 595-606. doi:10.1002/(sici)1097-

4679(200005)56:5<595::aidjclp2>3.0.co;2-q

Fryer, J. W., \& Elliot, A. J. (2007). Stability and change in achievement goals. Journal of Educational Psychology, 99, 700-714. doi:10.1037/0022-0663.99.4.700

German Federal Statistical Office/Statistisches Bundesamt (2016). Bildung und Kultur. Personal an Hochschulen. Fachserie 11, Reihe 4.4 [Education and culture. Higher education personell. Series 11, Issue 4.4]. Wiesbaden: Statistisches Bundesamt. Retrieved from https://www.destatis.de/DE/Publikationen/Thematisch/BildungForschungKultur/Hochschulen/PersonalHochschulen2110440167004.pdf

Giacalone, R. A., \& Promislo, M. D. (2014). Handbook of unethical work behavior: Implications for individual well-being. New York, NY: Routledge.

Gmelch, W. H. (1993). Coping with faculty stress. Newbury Park, CA: Sage.

Gnambs, T., \& Kaspar, K. (2015). Disclosure of sensitive behaviors across self-administered survey modes: A meta-analysis. Behavior Research Methods, 47, 12371259. doi:10.3758/s13428-014-0533-4

Gordon, G. (2005). The human dimensions of the research agenda: Supporting the development of researchers throughout the career life cycle. Higher Education Quarterly, 59, 40-55. doi:10.1111/j.14682273.2005.00280.x

Grant, H., \& Dweck, C. S. (2003). Clarifying achievement goals and their impact. Journal of Personality and Social Psychology, 85, 541-553. doi:10.1037/00223514.85.3.541

Gregorich, S. (2007). Do self-report instruments allow meaningful comparisons across diverse population groups. Medical Care, 44, 78-94. doi:10.1097/01.mlr.0000245454.12228.8f

Grossman, R., \& Salas, E. (2011). The transfer of training. International Journal of Training and Development, 15, 103-120. doi:10.1111/j.1468-2419.2011.00373.x

Harackiewicz, J. M. \& Sansone, C. (1991). Goals and intrinsic motivation: You can get there from here. Advances in Motivation and Achievement, 7, 21-49. doi:10.1037/0022-3514.65.5.904

Harrison, A. L., \& Kelly, D. G. (1996). Career satisfaction of physical therapy faculty during their pretenure years. Physical Therapy, 76, 1202-1218. doi:10.1093/ptj/76.11.1202

Hattie, J., \& Marsh, H. (1996). The relationship between research and teaching: A meta-analysis. Review of Educational Research, 66, 507-542. doi:10.3102/00346543066004507

Hemmings, B., \& Kay, R. (2010). Research self-efficacy, publication output, and early career development. International Journal of Educational Management, 24, 562574. doi:10.1108/09513541011079978

Hill, D., Rapoport, A., Lehming, R. F., \& Bell, R. (2007). Changing US output of scientific articles: 1988-2003. NSF-07-320), NSF, Arlington, VA. 
Hodgson, N. (2016). The researcher and the studier: On stress, tiredness and homelessness in the university. Journal of Philosophy of Education, 50, 37-48. doi:10.1111/1467-9752.12171

Hulleman, C. S., Schrager, S. M., Bodmann, S. M., \& Harackiewicz, J. M. (2010). A meta-analytic review of achievement goal measures. Psychological Bulletin, 136, 422-449. doi:10.1037/a0018947

Hurtz, G. M., \& Williams, K. J. (2009). Attitudinal and motivational antecedents of participation in voluntary employee development activities. Journal of Applied Psychology, 94, 635-653. doi:10.1037/a0014580

Jagacinski, C. M., Kumar, S., Boe, J. L., Lam, H., \& Miller, S. A. (2010). Changes in achievement goals and competence perceptions across the college semester. Motivation and Emotion, 34, 191-204. doi:10.1007/s11031010-9165-X

Jaksztat, S., Preßler, N., \& Briedis, K. (2012). Promotionen im Fokus. Promotions- und Arbeitsbedingungen Promovierender im Vergleich [Comparisons of Study and Work Conditions of PhD Students] (Forum Hochschule, Report No 15/2012). Hannover, Germany: HIS. Retrieved from http://www.dzhw.eu/pdf/pub_fh/fh-201215.pdf

Janke, S. \& Dickhäuser, O. (2018). A situated process model of vocational achievement goal striving within members of the academic staff at university. Motivation and Emotion, 42, 466-481. doi:10.1007/s11031-0179657-z

Janssen,O., \& van Yperen,N. (2004). Employees' goal orientations, the quality of leader-member exchange, and the outcomes of job performance and job satisfaction. Academy of Management Journal, 47, 368-384. doi:10.2307/20159587

Järvinen, J. (2017). How do students with different achievement goal orientation profiles perceive error climate in mathematics classroom? (Doctoral dissertation). Retrieved from https://helda.helsinki.fi/bitstream/handle/10138/222957/Gradu20170613_FINAL.pdf

Javitz, H., Grimes, T., Hill, D., Rapoport, A., Bell, R., Fecso, R., \& Lehming, R. 2010. U.S. academic scientific publishing. Working paper SRS 11-201. Arlington, VA: National Science Foundation, Division of Science Resources Statistics.

Kaplan, A., Middleton, M. J., Urdan, T., \& Midgley, C. (2002). Achievement goals and goal structures. In C. Midgley (Ed.) Goals, goal structures and patterns of adaptive learning (pp. 21-53). Mahwah, NJ: Erlbaum.

King, R. B., \& McInerney, D. M. (2016). Do goals lead to outcomes or can it be the other way around. British Journal of Educational Psychology, 68, 296-312. doi:10.1111/bjep.12107

Lackritz, J. R. (2004). Exploring burnout among university faculty. Teaching and Teacher Education, 20, 713-729. doi:10.1016/j.tate.2004.07.002

Landry, R., Lamari, M., \& Amara, N. (2003). The extent and determinants of the utilization of university research in government agencies. Public Administration Review, 63, 192 -205. doi:10.1111/1540-6210.00279

Lechuga, V. M., \& Lechuga, D. C. (2012). Faculty motivation and scholarly work: Self-determination and selfregulation perspectives. Journal of the Professoriate, 6(2). 59-97.

Lee, M., \& Bong, M. (2016). In their own words: Reasons underlying the achievement striving of students in schools. Journal of Educational Psychology, 108, 274294. doi:10.1037/edu0000048

Little, T. D., Cunningham, W. A., \& Shahar, G. (2002). To parcel or not to parcel. Structural Equation Modeling, 9, 151-173. doi:10.1207/s15328007sem0902_1

Little, T. D., Rhemtulla, M., Gibson, K., \& Schoemann, A. M. (2013). Why the items versus parcels controversy needn't be one. Psychological Methods, 18, 285-300. doi:10.1037/a0033266.

Litwin, J. (2014). Who's getting the biggest research bang for the buck. Studies in Higher Education, 39, 771-785. doi:10.1080/03075079.2012.754860

Maehr, M. L., \& Zusho, A. (2009). Achievement goal theory. In K. R. Wentzel \& A. Wigfield (Eds.), Handbook of motivation at school (pp. 77-104). New York, NY: Routledge.

Marsick, V. J., \& Watkins, K. (1990). Informal and incidental learning in the workplace. New York, NY: Routledge.

Mascret, N., Elliot, A. J., \& Cury, F. (2015). The 3 x 2 achievement goal questionnaire for teachers. Educational Psychology, 37, 346-361. doi:10.1080/01443410.2015.1096324

Maslach, C., Jackson, S. E., \& Leiter, M. P. (1996). Maslach burnout inventory manual. Mountain View, CA: CPP.

Maslach, C., \& Leiter, M. P. (2008). Early predictors of job burnout and engagement. Journal of Applied Psychology, 93, 498-512. doi:10.1037/0021-9010.93.3.498

Maslach, C., Schaufeli, W. B., \& Leiter, M. P. (2001). Job burnout. Annual Review of Psychology, 52, 397-422. doi:10.1146/annurev.psych.52.1.397

McGregor, H. A., \& Elliot, A. J. (2002). Achievement goals as predictors of achievement-relevant processes prior to task engagement. Journal of Educational Psychology, 94, 381-395. doi:10.1037//0022-0663.94.2.381

Minnaert, A. (2013). Goals are motivational researchers' best friend, but to what extent are achievement goals and achievement goal orientations also the best friend of educational outcomes. International Journal of Educational Research, 61, 85-89. doi:10.1016/j.ijer.2013.08.002

Murayama, K., Elliot, A. J., \& Friedman, R. (2012). Achievement goals. In R. Ryan (Ed.), The oxford handbook of human motivation (pp. 191-207). New York, NY: Oxford University.

Murayama, K., Elliot, A. J., \& Yamagata, S. (2011). Separation of performance-approach and performance avoidance achievement goals: A broader analysis. Journal of 
Educational Psychology, 103, 238-256. doi:10.1037/a0021948

Muthén, L., \& Muthén, B. (2017). Mplus (version 8.1) [Computer Software]. Los Angeles, CA: Muthén \& Muthén.

Nicholls, J. G. (1984). Achievement motivation. Psychological Review, 91, 328-346. doi:10.1037//0033295x.91.3.328

Nitsche, S., Dickhäuser, O., Fasching, M. S., \& Dresel, M. (2011). Rethinking teachers' goal orientations: Conceptual and methodological enhancements. Learning and Instruction, 21, 574-586. doi:10.1016/j.learninstruc.2010.12.001

Nitsche, S., Dickhäuser, O., Dresel, M., \& Fasching, M. S. (2013). Zielorientierungen von Lehrkräften als Prädiktoren lernrelevanten Verhaltens [Teachers goal orientations as predictors of vocational learning behavior]. Zeitschrift für Pädagogische Psychologie/Journal of Developmental and Educational Psychology, 27, 95103. doi: $10.1024 / 1010-0652 / \mathrm{a} 000092$

Nitsche, S., Dickhäuser, O., Fasching, M. S., \& Dresel, M. (2013). Teachers' professional goal orientations: Importance for further training and sick leave. Learning and Individual Differences, 23, 272-278. doi:10.1016/j.lindif.2012.07.017

Nolen, S. B. (1988). Reasons for studying: Motivational orientations and study strategies. Cognition and Instruction, 5, 269-287. doi:10.1207/s1532690xci0504_2

OECD (2018). Oslo manual. The measurement of scientific, technological and innovation activities $\left(4^{\text {th }} \mathrm{ed}\right.$.). Paris/Eurostat, Luxembourg: OECD Publishing

Padilla, M. A., \& Thompson, J. N. (2016). Burning out faculty at doctoral research universities. Stress and Health, 32, 551 -558. doi:10.1002/smi.2661

Papaioannou, A., \& Christodoulidis, T. (2007). A measure of teachers' achievement goals. Educational Psychology, 27, 349-361. doi:10.1080/01443410601104148

Parker, P. D., Martin, A. J., Colmar, S., \& Liem, G. A. (2012). Teachers' workplace well-being. Teaching and Teacher Education, 28, 503-513. doi:10.1016/j.tate.2012.01.001

Pasupathy, R., \& Siwatu, K. O. (2014). An investigation of research self-efficacy beliefs and research productivity among faculty members at an emerging research university in the USA. Higher Education Research \& Development, 33, 728-741. doi: $10.1080 / 07294360.2013 .863843$

Paulhus, D. L., Robins, R. W., Trzesniewski, K. H., \& Tracy, J. L. (2004). Two replicable suppressor situations in personality research. Multivariate Behavioral Research, 39, 303-328. doi:10.1207/s15327906mbr3902_7.

Payne, S. C., Youngcourt, S. S., \& Beaubien, J. M. (2007). A meta-analytic examination of the goal orientation nomological net. Journal of Applied Psychology, 92, 128150. doi:10.1037/0021-9010.92.1.128
Perkmann, M., Tartari, V., McKelvey, M., Autio, E., Broström, A., D'Este, P., \& Krabel, S. (2013). Academic engagement and commercialisation: A review of the literature on university-industry relations. Research Policy, 42, 423-442. doi:10.2139/ssrn.2088253

Perry, R. P., Clifton, R. A., Menec, V. H., Struthers, C. W., \& Menges, R. J. (2000). Faculty in transition. Research in Higher Education, 41, 165-194. doi:10.1023/A:1007091104399

Peugh, J. L., \& Enders, C. K. (2004). Missing data in educational research. Review of Educational Research, 74, 525-556. doi:10.3102/00346543074004525

Pintrich, P. R. (2000). An achievement goal theory perspective on issues in motivation terminology, theory, and research. Contemporary Educational Psychology, 25, 92104. doi:10.1006/ceps.1999.1017

Ponjuan, L., Conley, V. M., \& Trower, C. (2011). Career stage differences in pre-tenure track faculty perceptions of professional and personal relationships with colleagues. The Journal of Higher Education, 83, 319-346. doi:10.1080/00221546.2011.11777204

Praetorius, A.-K., Nitsche, S., Janke, S., Dickhäuser, O., Drexler, K., Fasching, M., \& Dresel, M. (2014). Here today, gone tomorrow. Contemporary Educational Psychology, 39, 379-387. doi:10.1016/j.cedpsych.2014.10.002

Retelsdorf, J., Butler, R., Streblow, L., \& Schiefele, U. (2010). Teachers' goal orientations for teaching. Learning and Instruction, 20, 30-46. doi:10.1016/j.learninstruc.2009.01.001

Sabagh, Z., Hall, N. C., \& Saroyan, A. (2018). Antecedents, correlates and consequences of faculty burnout. Educational Research, 60, 131-156. doi:10.1080/00131881.2018.1461573

Salmela-Aro, K., Tolvanen, A., \& Nurmi, J.-E. (2009). Achievement strategies during university studies predict early career burnout and engagement. Journal of Vocational Behavior, 75, 162-172. doi:10.1016/j.jvb.2009.03.009

Schermelleh-Engel, K., Moosbrugger, H., \& Müller, H. (2003). Evaluating the fit of structural equation models. Methods of Psychological Research Online, 8, 23-74. doi:10.1.1.509.4258

Schmitt, N., \& Kuljanin, G. (2008). Measurement invariance: Review of practice and implications. Human Resource Management Review, 18, 210 -222. doi:10.1016/j.hrmr.2008.03.003

Schmitz, B., \& Wiese, B. (2006). New perspectives for the evaluation of training sessions in self-regulated learning: Time-series analyses of diary data. Contemporary Educational Psychology, 31, 64-96. doi:10.1016/j.cedpsych.2005.02.002

Schneider, M., \& Preckel, F. (2017). Variables associated with achievement in higher education. Psychological Bulletin, 143, 565-600. doi:10.1037/bul0000098

Senko, C., \& Dawson, B. (2017). Performance-approach goal effects depend on how they are defined. Journal of 
Educational Psychology, 109, 574-598.

doi:10.1037/edu0000160

Senko, C., Hulleman, C. S., \& Harackiewicz, J. M. (2011). Achievement goal theory at the crossroads. Educational Psychologist, 46, 26-47. doi:10.1080/00461520.2011.538646

Singh, S. N., Mishra, S., \& Kim, D. (1998). Research-related burnout among faculty in higher education. Psychological Reports, 83, 463-473. doi:10.2466/pr0.1998.83.2.463

Stupnisky, R. H., BrckaLorenz, A., Yuhas, B., \& Guay, F. (2018). Faculty members' motivation for teaching and best practices: Testing a model based on self-determination theory across institution types. Contemporary Educational Psychology, 53, 15-26. doi:10.1016/j.cedpsych.2018.01.004

Stupnisky, R. H., Hall, N. C., Daniels, L. M., \& Mensah, E. (2017). Testing a model of pretenure faculty members' teaching and research success: Motivation as a mediator of balance, expectations, and collegiality. The Journal of Higher Education, 88, 376-400. doi:10.1080/00221546.2016.1272317

Stupnisky, R. H., Weaver-Hightower, M., \& Kartoshkina, Y. (2015). Exploring and testing predictors of new faculty success: A mixed method study. Studies in Higher Education, 40, 368-390. doi:10.1080/03075079.2013.842220

Terosky, A. L., \& Gonzales, L. D. (2016). Scholarly learning as vocation. Innovative Higher Education, 41, 105120. doi:10.1007/s10755-015-9341-8

Tönjes, B., \& Dickhäuser, O. (2009). Längsschnittliche Effekte von Zielorientierungen auf Dimensionen des beruflichen Belastungserlebens im Lehrberuf [Longitudinal effects of goal orientation on factors of occupational burden in the teacher profession]. Zeitschrift für Entwicklungspsychologie und pädagogische Psychologie/Journal of Developmental and Educational Psychology, 41, 79-86. doi:10.1026/0049-8637.41.2.79

Tönjes, B., Dickhäuser, O., \& Kröner, S. (2008). Berufliche Zielorientierungen und wahrgenommener Leistungsmangel bei Lehrkräften. Zeitschrift für pädagogische Psychologie, 22, 151-160. doi:10.1024/10100652.22.2.151

Trautwein, C., \& Merkt, M. (2013). Akademische Lehrkompetenz und Entwicklungsprozesse Lehrender [Academic teaching competence and development processes of lecturers]. Beiträge zur Hochschulforschung/Contributions to University Research, 35(3), 50-73. Retrieved from http://www.bzh.bayern.de/uploads/media/3-2013-Trautwein-Merkt.pdf

Tuominen-Soini, H., Salmela-Aro, K., \& Niemivirta, M. (2011). Stability and change in achievement goal orientations: A person-centered approach. Contemporary Educational Psychology, 36, 82-100.

doi:10.1016/j.cedpsych.2010.08.002
Urdan, T. (1997). Achievement goal theory. In M. L. Maehr \& P. R. Pintrich (Eds.), Advances in motivation and achievement, Volume 10 (pp. 99-141). Greenwich, CT: JAI.

Urdan, T., \& Mestas, M. (2006). The goals behind performance goals. Journal of Educational Psychology, 98, 354-365. doi:10.1037/0022-0663.98.2.354

Urdan, T., \& Turner, J. C. (2005). Competence motivation in the classroom. In A. J. Elliot \& C. S. Dweck (Eds.), Handbook of competence and motivation (pp. 297-317). New York, NY: Guilford.

van Yperen, N., Elliot, A. J., \& Anseel, F. (2009). The influence of mastery-avoidance goals on performance improvement. European Journal of Social Psychology, 39, 932-943. doi:10.1002/ejsp.590

van Yperen, N., \& Janssen, O. (2002). Fatigued and dissatisfied or fatigued but satisfied? Goal orientations and responses to high job demands. Academy of Management Journal, 45, 1161-1171. doi:10.2307/3069431

Volet, S. (2013). Extending, broadening and rethinking existing research on transfer of training. Educational Research Review, 8, 90-95. doi:10.1016/j.edurev.2012.11.005

Walker, G. J., \& Fenton, L. (2013). Backgrounds of, and factors affecting, highly productive leisure researchers. Journal of Leisure Research, 45, 537-562. doi:10.18666/jlr-2013-v45-i4-3898

Weinberg, B. A., Ownen-Smith, J., Rosen, R. J., Schwarz, L., Allen, B. M., Weiss, R. E., \& Lane, J. (2014). Science funding and short-term economic activity. Science, 344, 41-43. doi:10.1126/science. 1250055

Wormington, S. V., \& Linnenbrink-Garcia, L. (2017). A new look at multiple goal pursuit: The promise of a person-centered approach. Educational Psychology Review, 29, 407-445. doi: 10.1007/s10648-016-9358-2

Ziegler, A., Dresel, M., \& Stoeger, H. (2008). Addressees of performance goals. Journal of Educational Psychology, 100, 643-654. doi:10.1037/0022-0663.100.3.643

Zimmerman, B. J. (2000). Attaining self-regulation: A social cognitive perspective. In M. Boekaerts, P. R. Pintrich, \& M. Zeidner (Eds.), Handbook of self-regulation (pp. 13-39). San Diego, CA: Academic Press.

Note. This is a pre-copyedited, author-produced PDF of an article accepted for publication in Contemporary Educational Psychology following peer review. This paper is not the copy of record and may not exactly replicate the final, authoritative version of the article. The final article will be available, upon publication, via its DOI. 


\section{Footnotes}

${ }^{1}$ In terms of their time spent on research, we found in our samples that they did not differ substantially from the other academic staff members.

${ }^{2}$ Additionally, we ran all analyses separately for these three aspects of burnout/engagement and found very similar results.

${ }^{3}$ To ensure that the estimated parameters in this SEM are not biased because of multicollinearity problems, we compared the estimated parameters with the latent correlations between the corresponding variables. Also, we conducted backwards elimination by stepwise excluding all non-significant predictor effects. Additionally, for all significant parameters, we eventually systematically excluded one of them to see if the remaining effects were robust. These additional analyses revealed that appearance avoidance goals were only a negative predictor for burnout levels as long as task approach goals were also included in the same model. Together with the latent correlations that were not significant, this points to a suppressor effect that should not be interpreted in content (Paulhus, Robins, Trzesniewski \& Tracy, 2004). All other effects were robust and can be interpreted independently from other relations.

${ }^{4}$ Three participants did not provide answers about their academic status.

${ }^{5,6}$ Correlations between all assessed variables are provided in the supplement (Table S4). 